\title{
On Perceived Exertion and its Measurement
}

\author{
Elisabet Borg
}

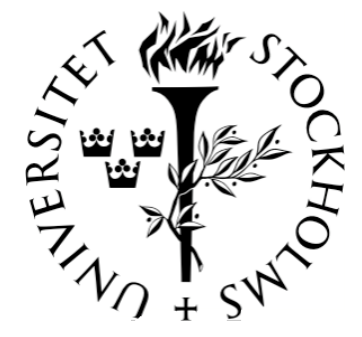

Department of Psychology

Stockholm University

2007 
Doctoral dissertation, 2007

Department of Psychology

Stockholm University

Sweden

Cover illustration: Elisabet Borg

(C) 2007 Elisabet Borg

ISBN 978-91-7155-456-7

US-AB, Stockholm 2007 
To my father 


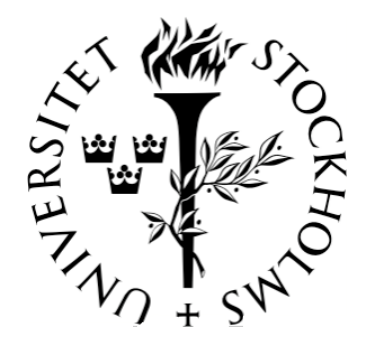

\begin{abstract}
The general aim of the thesis is to answer questions on general and differential aspects of perceived exertion and on the measurement of its intensity variation. Overall perceived exertion is commonly treated as a unidemensional construct. This thesis also explores its multidimensional character. Four empirical studies are summarized (Study I-IV). Psychophysical power functions of perceived exertion obtained with the new improved Borg CR100 (centiMax) scale were found to be consistent with results obtained with absolute magnitude estimation, and with the classical Borg CR10 and RPE scales. Women gave significantly higher perceived exertion scale values than men for the same levels of workload on a bicycle ergometer. This agrees with the fact that they were physically less strong than men. With regard to the measurement of "absolute" levels of intensity, RPE- and CR-scale values were validated by physiological measurements of heart rate and blood lactate. Predicted values of maximal individual performance obtained from psychophysical functions agreed well with actual maximal performance on the bicycle ergometer. This confirms the validity of the RPE and CR scales for measuring perceptual intensity and their value for interindividual comparisons. To study the multidimensional character of perceived exertion, 18 symptoms were measured with a CR scale: in a questionnaire, and in bicycle ergometer work tests. Five factors were extracted for the questionnaire: (1) Muscles and joints; (2) Perceived exertion; (3) Annoyance/lack of motivation; (4) Head/stomach symptoms; and (5) Cardiopulmonary symptoms. Four factors were extracted for the bicycle max test: (1) Physical distress; (2) Central perceived exertion; (3) Annoyance/lack of motivation; (4) Local perceived exertion. The questionnaire is suggested for clinical use to let patients express a variety of symptoms. The thesis also resulted in improvements of the Borg CR100 scale. An extended use of the scale is recommended.
\end{abstract}

Key words: Perceptual scaling, psychophysics, Category-Ratio scale, perceived exertion, interindividual comparisons 


\section{List of studies}

The present thesis is based on the following studies, which are referred to in the text by their Roman numerals:

Study I Borg, E., and Borg, G. (2002). A comparison of AME and CR100 for scaling perceived exertion. Acta Psychologica, 109, 157-175.

Reprinted from Acta Psychologica, with permission from Elsevier.

Study II Borg, E., and Kaijser, L (2006). A comparison between three rating scales for perceived exertion and two different work tests. Scandinavian Journal of Medicine in Science and Sports, 16: 57-69.

Reprinted from Scandinavian Journal of Medicine in Science and Sports, with permission from Wiley-Blackwell Publishing.

Study III Borg, E. (manuscript). Individual differences in perceived exertion assessed with the Borg RPE, CR10, and CR100 scales.

Study IV Borg, E. (manuscript). Interindividual assessment of multidimensional symptoms of perceived exertion. 


\section{Glossary}

Absolute magnitude estimation

Annoyance

Bicycle ergometer

Blood lactate

Borg CR10 scale

Borg CR100 (centiMax)

scale

Borg RPE scale

Borg's Range Model

Category scale

Central factors of

perceived exertion

Constrained scaling

Distal stimulus

Exertion

Heart rate

Joint scaling

Label

Local factors of perceived exertion

Magnitude estimation

Magnitude matching similar to magnitude estimation, but with the additional instruction that participants should use numbers so that they match perceptions of number "intensity" with that of the intensity of the stimulus. Intended to handle interindividual differences and give "absolute" levels of intensity

an unpleasant feeling related to irritation

exercise device resembling a bicycle, constructed to measure the amount of work performed (usually as a power level expressed in Watt)

produced as a natural part of the carbohydrate metabolism, suggested to play a major role (even if not directly causal) in "muscle fatigue" and the pain experienced during exercise. Usually measured in milliMolar $(\mathrm{mM})$

a general scale for perceived intensity. Category scale with Ratio scale properties, 0 - 10

a general intensity scale. Category scale with Ratio scale properties, 0 100 centiMax units

category scale for Ratings of Perceived Exertion with interval scale properties, constructed to give measurements that grow linearly with aerobic demands

a theoretical model enabling interindivdual comparisons by postulating the total natural, subjective dynamic range, to approximately the same for most individuals

a scale with its scale values in the form of response categories

proximal stimuli from the cardio-pulmonary system

for some chosen modality participants are taught and trained in the use of a certain standard scale with a specific exponent of the psychophysical power function, until they are able to reproduce the chosen exponent with high accuracy. The same participants the scale perceptual magnitudes of target stimuli with this same scale

stimulus from the outer world

use of physical (or mental) energy to accomplish something

the frequency of the cardiac cycle, usually calculated as the number of heart beats in one minute (bpm)

to jointly scale two (or more) sets of stimulus qualities, each varying in intensity, for example, two kinds of odor qualities, or different sound frequencies, in the same experimental session (see magnitude matching and master scaling)

a tag attached to something for identification

proximal stimuli from, e.g., the skin, working muscles, and joints

a perceptual scaling technique where participants are instructed to assign numbers in relation to perceptual intensities so that an intensity level that is perceived as twice as intense as second intensity level is assigned a number twice as large as the first one, etc.

perceptions of sets of stimuli are estimated with magnitude estimation 
Master scaling

Maximal performance

Measurement

Objective

Oxygen consumption

\section{Perceived exertion}

Percentage ratings

Perception

Proximal stimulus

Psychometrics

Psychophysics

Rate (verb)

Rating (noun)

Scale (noun)

Scale (verb)

Sensation

Subjective

Sub-maximal

performance

Visual Analogue Scale

Work capacity on a "common" numerical scale, shifting between two (or more) stimulus modalities

participants scale a set of reference stimuli with known stimulus values jointly with target stimuli (for which stimulus intensities need not be known). Individual psychophysical functions for references are used together with a master scale (postulated or empirical) for calibrating each individual's scale so that perceptions of target stimuli are expressed in units of the master scale

the highest performance physically possible for an individual, usually measured in units of the physical stimuli, e.g., as a power level in Watt on a bicycle ergometer

"the assignment of numerals to objects or events according to rules" (S. S. Stevens, 1946)

non-subjective, neutral, detached

volume of oxygen that the body consumes during exercise, usually measured in liters per minute $(\mathrm{L} / \mathrm{min})$ or milliliters per $\mathrm{kg}$ bodyweight per minute $(\mathrm{ml} / \mathrm{kg} / \mathrm{min})$

the perception of how the body is working during exercise, a "Gestalt" based on many sensory cues and perceptions

ratings given in percent of a defined maximal level (either perceived or conceived of)

brain making "sense" of what our sensory systems tell us; the active process of organizing the resulting sensory information and give it meaning

stimulus originating from within the physical human body

the field within psychology primarily concerned with the measurement of individual or group differences in knowledge, abilities, attitudes and personality traits

the field within psychology studying how sensations and perceptions relate to the physical world and how sensations relate to each other

to give a number, label, or mark on a scale as a measurement of a perception

a given number, label or mark on a scale as a measurement of a perception

a measuring tool, also the result of scaling some perceptual attribute

to give numbers as measures of perception according to, e.g., ratio scaling principles

the stimulus "recording" process by which our sense organs respond to and translate environmental stimuli into nerve impulses that are sent to the

individual, personal

an individual physical performance at a specified level somewhere below the individual's maximum, usually measured in units of the physical stimuli, e.g., as a power level in Watt on a bicycle ergometer

a perceptual intensity scale constructed as a line with two endpoints, often labeled "Noting at all" and "Strongest imaginable"

a measure of a person's physical capacity, usually measured as a performance on a certain exercise equipment, e.g., measured in Watt on the bicycle ergometer. Often maximal performance is measured, but sometimes also sub-maximal 


\section{Symbols and abbreviations:}

bpm

CR

HR

$\left[\mathrm{La}^{-}\right]$

$\mathrm{R}$

RPE

$\mathrm{S}$

VAS

$\hat{\mathrm{V}} \mathrm{O}_{2}$

$\mathrm{W}_{170}$

$\mathrm{W}_{\mathrm{R} 17}, \mathrm{~W}_{\mathrm{R} 7}, \mathrm{~W}_{\mathrm{R} 70}$ beats per minute (unit for heart rate)

Category Ratio (CR)

Heart Rate in bpm

concentration of blood lactate ions (mM)

Response variable

scale for Ratings of Perceived Exertion

Stimulus variable

Visual Analogue Scale

oxygen consumption ( $`$ implies an estimated value)

a sub-maximal measure of work capacity estimated from an individual heart rate of 170 beats/minute, e.g., by using HR-S relationship

a sub-maximal measure of work capacity estimated from individual psychophysical functions for $\mathrm{RPE}=17, \mathrm{CR} 10=7$ and $\mathrm{CR} 100=70$ respectively, $\mathrm{R}$ stands for the response variable 


\section{Contents}

1. INTRODUCTION 15

1.1. The perceptual process $\quad 15$

1.2. Measurement and perceptual scaling 16

1.3. Measurement and individual differences 18

2. UNIDIMENSIONAL SCALING 19

2.1. Category scaling and verbal expressions 19

2.2. Magnitude estimation $\quad 20$

2.3. How to handle individual differences in scaling? 22

2.3.1. Absolute magnitude estimation (AME) 23

2.3.2. Joint scaling 23

2.3.3. Constrained scaling 24

2.3.4. Borg's Range Model 24

2.4. The Borg RPE scale ${ }^{\circledR}$ and Borg CR10 scale ${ }^{\circledR}$ for perceptual scaling 25

2.5. Other CR scales $\quad 27$

2.6. The Borg CR100 (centiMax) scale ${ }^{\circledR} \quad 28$

3. PERCEIVED EXERTION 30

3.1. The perceptual domain $\quad 30$

3.2. The physiological domain 31

3.3. The performance domain 32

4. AIM OF THE THESIS

5. SUMMARY OF THE STUDIES

5.1. A comparison of AME and CR100 for scaling perceived exertion (Study I) 33

5.1.1. Psychophysical and psychophysiological function 34

5.1.2. Individual differences and separate levels of intensity 34

5.1.3. Specific scale properties $\quad 34$

5.1.4. General conclusions

5.2. A comparison between three rating scales for perceived exertion and two different $\begin{array}{ll}\text { work tests (Study II) } & 34\end{array}$

5.2.1. Psychophysical and psychophysiological functions 35

5.2.2. Specific scale properties

5.3. Individual differences in perceived exertion assessed with the Borg RPE, CR10 and CR100 scales (Study III) $\quad 35$

5.3.1. Psychophysical and psychophysiological functions 36

5.3.2. Individual differences and direct levels of intensity 36

5.3.3. Specific scale properties 37 
5.4. Interindividual assessment of multidimensional symptoms of perceived exertion (Study IV)

5.4.1. Individual differences and direct levels of intensity 37

5.4.2. Symptoms profiles and dimensionaltiy 37

6. DISCUSSION 38

6.1. General and individual psychophysical functions (Study I and Study II). 38

6.2. Interindividual comparisons and direct level estimates (Study I, Study III and Study IV). 39

6.2.2. For multidimensional symptoms of perceived exertion

6.2.3. Prediction of gender and physical fitness

6.3. Borg's Range Model, enhancing assessments of individual differences (Study I, Study III and Study IV)

6.4. Perceived exertion in daily activities and sports activities (Study IV).

6.5. The multidimensional character of perceived exertion (Study III and Study IV) 43

6.6. General methodological issues 46

6.6.1. Representativness of cases 46

6.6.2. Generalizability of results 47

6.6.3. Reliability 47

6.6.4. Validity $\quad 47$

6.7. Criticism of perceptual scaling 48

6.8. Final adjustments of the Borg CR100 (centiMax) scale 49

6.9. Areas of application $\quad 50$

Acknowledgment $\quad 51$

References $\quad 52$

$\begin{array}{ll}\text { Appendix } & 57\end{array}$ 


\section{INTRODUCTION}

A light passes through our eye via complicated neural transduction processes and into our brain. It reaches our mind, we "see" a red light, consciously perceives it as being a traffic light, and stop our car. A smell, a sound, a taste, a touch, and so on, similarly usually originate from distal stimuli in the outer world, -they demand our attention, are sensed and perceived. But we are not just passive receivers of information through our senses. We actively react to, interact with and act in accordance with the world we perceive. Our actions, in turn can be viewed as stimuli, blending with proximal stimulation, being sensed, perceived and acted upon. We adjust the intensity of our voice in relation to the sounds we perceive and speak louder outdoors on a noisy street than indoors. We adjust the effort with which we run to the bus, while perceiving how our muscles work, our panting rises and sweat breaks out in our forehead. When we see the bus coming round the corner, we will exert ourselves at our maximum - we really need to take that bus! - and, once we are on the bus, our legs are aching, our heart is pounding heavily and we are gasping for "breathlessness".

\subsection{The perceptual process}

Sensation is sometimes defined as the stimulus "recording" process by which our sense organs respond to and translate environmental stimuli into nerve impulses that are sent to the brain. Conversely, perception is making "sense" of what our sensory systems tell us, the active process of organizing the resulting sensory information and give it meaning. Often, however, the two terms are used with some overlap in meaning (e.g., Coren, Ward and Enns, 1994; Passer and Smith, p. 110, definition in Pashler and Yantis (Eds), 2002.)

Somewhat simplified our behavior can be said to originate from a combination of external and internal cues and processes. A response to a stimulus is thus a function of an interaction among stimulus' qualities and individual factors. The general perceptual process could be illustrated as in Figure 1. In our sensory/perceptual system, sensory receptors translate different stimuli into nerve impulses. It may be distal stimuli, from the outer world, or proximal stimuli, from our muscles, joints and inner organs. The brain receives the nerve impulses, organizes them, compares the representations with previously stored information in memory, assigns meaning to them by matching processes and creates a sensation of say, a read light. Depending, for example, on the intensity and "importance" of the incoming stimulus event it may or may not become a perceptual experience, first of detecting that something is there and then maybe also identifying what that something is, for example "a red traffic light". Then, if necessary, some kind of response reaction is activated or chosen, like a performance or a judgment. Moreover, emotions and bodily reactions to the stimuli will in turn act like proximal stimuli and affect the reaction. This is especially true when physically moving the body, because the regulation of movement also depends upon feedback from the moving body. Gunnar Borg (1962) thus defined the perception of exertion as a "Gestalt" consisting of many contributory factors as sensations "from the muscles, the skin, the joints, etc." together with perceptions of "pedal resistance, effort, fatigue, strain exertion, heat, pressure, pain or anxiety, etc." 


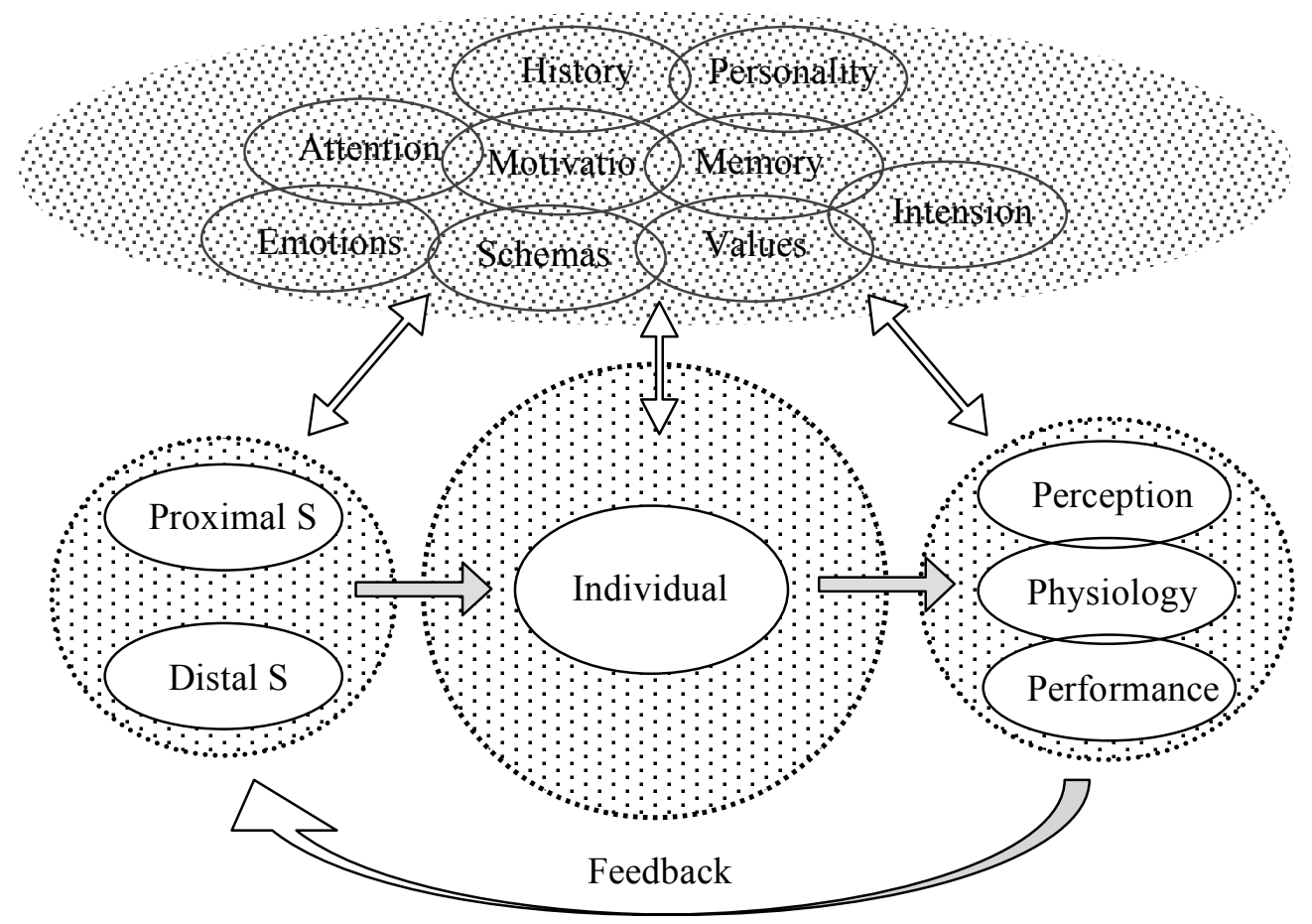

Figure 1. A general model of sensory-perceptual processes. The "response" may be a perception, a performance, or a physiological variable (cf. G. Borg, 1998). [S stands for stimulus].

Along the perceptual process the individuals' different cognitive powers are of course also at work. And, the context of the stimuli presentations and of the individuals' situation may influence the outcome in different ways. I once stopped at a crosswalk to let two women with a pram cross the street. When they were safe on the other side I drove pass them, with that slightly pleasant feeling of having done a good deed. When I was passing them, however, they stared at me with an upset frown and not at all in gratitude, causing me to look back in the mirror. Guess if I was surprised when I then saw that there was a red traffic light! I still don't know if the lamps were perhaps broken on the side where I came from, or if I just didn't "see" it.

\subsection{Measurement and perceptual scaling}

Measurement may be defined as "the assignment of numerals to objects or events according to rules" This is a very broad definition and was a reaction from Stanley S. Stevens against the desire to tie all measurement to the formal rules of arithmetic additivity (S. S. Stevens, 1946, 1975). In a more recent review article, Hand (1996) discusses three main theories of measurement: the representational theory, where numbers are assigned to objects to model their relationships, the operational theory where numbers are assigned according to some consistent measurement theory, and the classical theory where pre-existing relationships are discovered.

It is important that the measurement process and its results are valid, meaning that the outcome is "true" to the construct measured. Validity can be discussed from many aspects and is often rather difficult to assess (see, e.g., Cook and Campbell, 1979; Messick, 1995). Apart from being valid, the outcome of a measurement should be reliable. For example, one would expect internal consistency as well as consistency over time (stability). 
As mentioned above oral, physiological and performance responses can be said to originate from a combination of stimulus factors (distal and proximal) and individual/personal resources. Thus, there are three possible ways to view the outcome of a psychological measurement: First, the systematic variation in responses between persons may be attributed mainly to individual differences (person variance). This is typically studied in psychometry and item-response theory. It is, for example, used in person-oriented research and in personality research. Secondly, the systematic variation in responses may be attributed mainly to variations in the environment (stimulus variance), as, for example, when evaluating an individual's auditory threshold or when studying how the perceived intensity of a light relates to the physical luminance. Thirdly, a combination of the two is possible if systematic variation in responses to stimuli is attributed both to individual differences and variations in the environment (individual-stimulus interaction) as, for example, often is the case in medicine, ergonomics and sports.

The two last alternatives are studied with psychophysical methods. It is usually considered that the area of psychophysics was founded in 1860 with the publication of Gustav T. Fechner's Elemente der Psychophysik. Psychophysics is the science of how sensations and perceptions relate to the physical world and how sensations relate to each other. Thus questions about absolute thresholds, just noticeable differences between two stimuli, sensory processing, and relationships between physical and perceived intensities of stimuli are addressed with psychophysical methods. More specifically perceptual scaling deals with the last of these three questions (see, e.g., Marks and Gescheider, 2002).

To scale something, you need some kind of rule, usually in the form of a measuring tool with a unit, by which you can order systematically the objects or events to be measured. Large amounts of scales exist for measuring in the natural sciences, usually with arbitrary units, such as is the case in, for example, the metric system. Depending on what is being measured and what mathematical transformations are admissible, different types of scales are possible (S. S. Stevens, 1946, 1975). Firstly, the most primitive type is the nominal scale allowing only for a classification of objects into different groups according to similarity and difference. The values obtained on such a scale, nominal data, are thus just identity codes, for groups of objects of events. Secondly, there is the ordinal scale allowing for a ranking of objects or events along some dimension. You may, for example, order your beefsteak on a scale from rare, medium rare, to well done. And on this "how-well-done dimension" you may say that "rare" is less than "medium rare" that is less than "well done". Thirdly, there is the interval scale. This scale allows for equal intervals between what is being measured, but zero is just another point on the scale and not equal to zero amount of what is being measured. The Celsius and Fahrenheit scales for temperature are good examples. Thus the difference between $10^{\circ} \mathrm{C}$ and $25^{\circ} \mathrm{C}$ is three times the difference between $5^{\circ} \mathrm{C}$ and $10^{\circ} \mathrm{C}$ (and this is also true if all temperatures are changed to the Fahrenheit scale). The fourth scale is the ratio scale with an absolute zero, for zero amount of what is being measured, thus also making ratios between scale values meaningful. Scales used for length and weight, are examples of ratio scales. A stone that weighs $40 \mathrm{~kg}$ can be said to weigh twice as much as one of $20 \mathrm{~kg}$, which correspondingly, is true also for pounds; a temperature of $400 \mathrm{~K}\left(127^{\circ} \mathrm{C}\right)$ is twice as much as $200 \mathrm{~K}\left(-73^{\circ} \mathrm{C}\right)$. The fifth scale is the absolute scale, also with an absolute zero, but where the only permissible transformation is numerical identity. Numerosity is measured on an absolute scale. Number of participants is an example, since, 200 participants are 200 participants and cannot be measured in any other way without loss of information. (cf. Marks, 1974). 


\subsection{Measurement and individual differences}

In psychometric methods, individual differences are usually studied by creating tests with known answers to test items (stimuli). An individual, who answers correctly to a specific item, is regarded as possessing more of whatever quality the item is assumed to measure, than does someone whose answer is wrong. The individual answer to an item is typically, considered to be a linear function of the "true" individual score and a random error (of individual and environmental factors). Individual differences with regard to the quality measured by the test can then be at least rank ordered by the individuals' total test scores. Often test results are assumed as linearly related to the quality measured, and test scores are then treated as belonging to an interval scale (e.g., Lord and Novick, 1968).

For sensory variables, studied in psychophysics, the assumption is often made that, to some extent, human beings can function as "measuring instruments". Our senses are good tools for detecting and identifying states and changes in our environment. As a first assumption, sensory processing can be considered to be similar across individuals. Observed deviations are then usually regarded as inherent deficits or limitations, either in sensory processing or in individual "measurement behavior" (in giving ratings or scaling). The special ability of our senses to register changes enables us, not just to order states, but also to scale them. A continuous increase in stimulus intensity is paralleled with a continuous increase in sensory reaction. Perceptions are assumed to be monotonically related to sensations that in turn are monotonically related to physical intensities.

If a "true" sensory processing may be assumed, perceptual measurement may be used to study changes in stimulus intensities. An important prerequisite is that individual differences in the measurement values are viewed as "random errors".

Somewhere on the way through our sensory system something seems to happen. We may, for example, perceive the loudness of one physical sound intensity, as less than the double of another physical sound intensity, twice its size; and, correspondingly, the heaviness of a lifted weight as more than the double of the weight that weighs twice as much. This is likely related to the fact that our senses seem to be tuned to cover a wide variety of dynamic stimulus ranges from very large ones, as for sound and light, to very small ones, as for electric chock (R. Teghtsoonian, 1971). More recent research by Nieder and Miller (2003) on visual numerosity in rhesus monkeys has shown a nonlinear compression on the neural level, supporting this psychophysical nonlinearity. Also, Johnson, Hsiao, and Yoshioka (2002) found support for linearity between neural activity and subjective experience in texture perception in a design that did not need any assumptions about the form of the psychophysical law.

If there exist systematic individual differences at any level in the general model of the sensory-perceptual process (Figure 1), the assumed "random errors" will not be random. This would, of course, be the case for persons with different sensory deficits, or if some other systematic difference exists in measurement behavior between individuals, for example, depending on cognitive resources and education. One way to handle such problems may be by careful sampling of participants in order to control for such "confounders". This has not been common practice in psychophysical research, even though S. S. Stevens spoke of the "ideal observers" (S. S. Stevens, 1975).

How would it be possible to decide upon whether an individual variation in psychophysical 
responses is a result of a nonrandom individual difference? How can we separate a true individual component from a random one? One way to answer these questions might be by systematic variation of background variables, such as education and intelligence, suspected as confounders affecting individual responses. This way of studying measurement behavior was attempted by G. Borg and E. Borg (1992). They found that education and results on some aptitude tests co varied with perceptual measurements. Another way to answer the two questions would be by means of analogies from physiology. If there are sensory differences among individuals or groups of individuals, individual differences in perceptual measurements may also be expected. An example of this may be found in taste perception for non-tasters, tasters, and super-tasters (Bartushuk, 2000) or in odor perception for smokers and nonsmokers (B. Berglund and Nordin, 1992).

Thus, the first assumption in psychophysics must be that of similarity in sensory processing supplemented with that averaging over large enough numbers of "exposures" cancels out the estimation errors of the stimulus, and that averaging over large enough groups of "normal" subjects makes away with individual errors in measurement behavior. When general psychophysical knowledge is ones obtained, one should then be able to use it to study individual differences as deviations.

\section{UNIDIMENSIONAL SCALING}

Several techniques exist for relating perceptual intensities to physical intensities. Indirect scaling procedures are based on discrimination ability, typically using just noticeable differences (JND) as unit. In direct scaling procedures, individuals are instead asked to assign a value to the magnitude of the perception. Two popular direct methods are category scaling and magnitude estimation. In category scaling, all categories should be the same so that intervals between category boundaries are perceptually equal. In magnitude estimation, individuals assign numbers to stimuli in relation to how intense they appear to be (e.g., S. S. Stevens, 1975; Coren, Ward and Enns, 1994).

\subsection{Category scaling and verbal expressions}

"I like weak coffee, but this is probably the best coffee I ever had". The story was one of my grandmothers' favorites, and it illustrates something interesting and important: since the oldest history of humanity, language has been used as a tool to communicate both levels of intensities as well as relations among them.

As children grow up, adjectives and adverbs are given meaning by personal experiences and gradually schematized, given natural positions in an inner frame of reference (cf. e.g., Sternberg, 2006). Daily language consists of many expressions describing perceptual intensity levels with high interpersonal agreement (between most persons in most normal situations and in similar cultural settings). Maybe you can recall a quarrel with your grandmother at the dinner table about the amount of salt in the soup? When you complain that the soup is too salty, and she just brushes your complaints away as "Rubbish!", your first thought wouldn't be: "Well, we probably don't mean the same thing with 'very salty", but rather "As I believe we do mean the same thing with 'very salty', I must assume that Granny's taste buds are getting old and that this soup doesn't taste 'very salty' to her anymore!'

This is why simple "rating scales" (often with 5 to 9 verbal expressions) have obvious 
advantages and are still widely used (Guilford, 1936, 1954). There are, however, some weaknesses with verbal category scales. One weakness is the problem of knowing whether labels really mean the same to different people. You and I might both smile at the coffeestory, but confronted with the actual cup of coffee I (adapted to Swedish coffee) might say "well, a little weak, but nice", while you (especially if you're from the United States) might say, "who killed that cat?" Still, in the coffee-discussion that would likely follow, we would probably agree that it is our preferences, and maybe also our perception, but not our sensation that differs. But we can't really know, can we?

Another obvious problem is the metric properties. The scales do not give information about the relations between the verbal categories (i.e., of how much stronger "moderate" is than "weak", etc). When instructed to use the categories as representing equal distances, they might at the best give results on interval scale level (see Marks, 1974, S. S. Stevens, 1975, Marks and Gescheider, 2002). Such instructions are, however, seldom given, and even if they were, participants would only follow them to the extent they find them consistent with their own understanding. This leaves room for an individual interpretation of the actual relationship among the categories. It also affects assumptions of normality of the data obtained. Even if a normal distribution is obtained for ordinal-scale data, there is no way of knowing if the perceptions beneath are really normally distributed. Therefore some claim that such scales can only with certainty be said to render ordinal data (Svensson, 1998, 2000).

In medicine a commonly used scale, especially in pain assessment, is the so-called VAS (Visual Analogue Scale). It consists of a straight line often anchored at the endpoints with expressions such as "minimal" and "maximal" (or "highest imaginable"). The participant is instructed to give a judgment with a mark on the line. The method may have interval properties and has even been postulated to work as a ratio scale (Price, McGrath, Rafii and Buckingham, 1983). This has, however, been met with criticism, as has the assumption of congruence in meaning of scale values (Svensson, 1998, 2000; Williams, Davies and Chadury, 2000). The VAS has also been found to be subject to end effects (Neely, Ljunggren, Sylvén and G. Borg, 1992; Neely and E. Borg, 1995).

\subsection{Magnitude estimation}

In the middle of the last century S. S. Stevens and his collaborators at Harvard University began using a direct estimation methodology for ratio scaling of physical intensities, earlier used by Richardson and Ross (1930) on loudness of telephone signals. S. S. Stevens and colleagues coined the method magnitude estimation and the basic principle is that participants may freely use numbers that they match to the intensity of what is being judged. "All measurement involves the matching of an aspect of one continuum to an aspect of another continuum. In the method of magnitude estimation the observer brings one of the continua with him as the system of numbers that he has learned so very thoroughly in memorizing the multiplication table, in counting change, and in measuring many things. With the number system thoroughly drummed into him, the observer can match numbers from that continuum to any other continuum with which he is confronted" (S. S. Stevens 1975, p. 30). With ratio methods, such as magnitude estimation, relations among sensations may be directly assessed. The method was proved to work well and led to the possibility of scaling different sensory modalities and to the development of Stevens' law, according to which the growth of sensations $(\psi)$ with increasing physical stimulus intensity $(\phi)$ can be described by a power function: 


$$
\psi=\mathrm{k} \phi^{\mathrm{b}}
$$

or, if we choose to be a little more cautious, as:

$$
\mathrm{R}=\mathrm{cS}^{\mathrm{n}}
$$

where $\mathrm{S}$ is the stimulus variable and $\mathrm{R}$ is merely the response variable, $\mathrm{c}$ is a multiplicative constant and $\mathrm{n}$ is the exponent. Several modalities were investigated and their exponents determined, and the technique was shown to work well for this purpose (S. S. Stevens, 1957, 1975; S. S. Stevens and Galanter, 1957).

The power function (Equation 1) was further developed by G. Ekman, who in 1959 suggested two alternatives to deal with the absolute threshold (cf. Corso, 1963). When the stimulus threshold is found to be above zero stimulation:

$$
\mathrm{R}=\mathrm{c}(\mathrm{S}-a)^{\mathrm{n}}
$$

or, when there is "perceptual noise" at zero stimulation:

$$
\mathrm{R}=a+\mathrm{cS}^{\mathrm{n}}
$$

S. S. Stevens later agreed that such a constant was sometimes necessary, even for loudness: "The accumulated evidence has forced a change in my own view, so that when a translation is called for, I now favor translation on the stimulus axis" (S. S. Stevens, 1975, p. 292). Even if the distal stimulus is zero, the proximal stimulus originating in some bodily activity may, even at rest, be above zero, resulting in "perceptual noise". In other cases the opposite may occur, and the proximal stimulus be zero even when the distal stimulus is above zero. Gunnar Borg (1961, 1962, see also Marks and J. C. Stevens, 1968), thus proposed to include two basic constants to represent perceptual "noise" and the starting point of the power growth, $a$ and $b$, or alternatively, to denote the absolute threshold $\left(\mathrm{R}_{0}\right.$ and $\left.\mathrm{S}_{0}\right)$ :

$$
\mathrm{R}=a+\mathrm{c}(\mathrm{S}-b)^{\mathrm{n}}
$$

Often the constant $(a)$ or the constant $(b)$, or both, take on the value of zero, but in some cases as with perceived exertion during walking, both constants take on values above zero (G. Borg, 1973a). The equation can also be used to describe the growth of physiological variables, e.g., the growth of blood lactate (G. Borg, 1961, 1962, 1991, Mountcastle, Poggio and Werner 1963).

An interesting question is if the power law only describes perceptual responses given with magnitude estimation, or if it also has foundation in neurological transduction. Support for the power function at a neural level, was found by G. Borg, Diamant, Ström and Zotterman (1967) for responses from the taste nerve, and more recently by Nieder and Miller (2003) on visual numerosity in rhesus monkeys. On the other hand, Knibestöl and Vallbo (1980), found no correlation between individual power function exponents from single nerve fibers and from magnitude estimation, and Laming (1997) argues that neural data tells nothing on the subject of psychophysiology.

Difficulties involved in perceptual scaling have been, for example, choice of response method, individual number behavior, experimental design, context effects, memory effects, 
sequential effects, etc., all affecting both the perception and the judgment and sometimes even the sensation. Scaling methods and the power function have received criticism. Some even question whether a relation between stimulus magnitude and sensory magnitude actually exists (see e.g., Algom and Marks, 1990; Baird and Noma, 1978; Coren, Ward and Enns, 1994; Gescheider, 1997; Laming, 1997; Lockhead, 1992, 2004; Luce and Green, 1974; Poulton, 1968, 1989; Schneider and Parker, 1990).

Psychology as a whole, not only scaling, has been criticized for focusing too much on measurement issues, not paying enough attention to the "scientific" task of "showing that the relevant attribute is quantitative" (e.g., Michell, 1997). Apart from the scaling approach, however, a more mathematical approach to psychological measurement exists. This is the axiomatic approach, with the objective to develop a measurement system based on mathematical axioms. With the assumption that the inner psychological structure is homogenous, i.e., uniform throughout, it seems to justify the measurement of perceived intensity. This also supports the belief that magnitude estimation is measurement at the level of ratio scales (Luce and Krumhansl, 1988, Luce, 1990; 1997; Narens, 1996).

On the other hand, since the power function for perceived intensities describes empirical data in an excellent way, it is appealing to adopt the viewpoint suggested by Ward (2006). That is, to regard the "power law" as an "ideal law" in analogy with what has often been done in physics (e.g., the ideal gas law). Such a law only applies under certain ideal conditions that may never be met, but it still gives a very good approximation.

\subsection{How to handle individual differences in scaling?}

Already Richardson and Ross (1930) found individual differences, in loudness exponents ranging from 0.24 to 1.1 , implying that "a telephone current 10 times stronger than the standard is, on the average [with a mean exponent of approx. 0.5], judged to produce a sound three times as loud, but the extreme estimates are 1.7 times and 13 times as loud as the standard." They concluded that two explanations were possible: "(a) sensations [are] the same for all persons, divergent estimates wrong, or (b) sensations [are] really different for different persons, estimates showing this fact", but did not take a stand to which explanation was the more likely.

S. S. Stevens regarded the individual mainly as a measuring instrument adopting the assumption that there is little to support individual differences at a sensory level for healthy people (S. S. Stevens, 1971). Thus, interest was primarily focused on relative growth functions and group exponents. The individual variation obtained was primarily regarded as random noise depending upon individual measurement behavior that could be dealt with by averaging over individuals. To what extent this is true, is, of course, a very tricky question. It is, however, the logical starting point for examination. It is impossible to study deviations if you do not first study similarity. As an example, there would be no problem with overweight people if there were no range of weights that was normal - and healthy - for humans. Ones you've found out what that is, studying individual differences may be interesting.

Jones and Marcus (1961) suggested an individual component, as part of the exponent in the psychophysical power function, to explain consistently individual differences in exponents found for weight, taste and smell. G. Borg and Marks (1983) included an individual component among the "twelve meanings of the measure constant", c (Equation 1-4). The individual component may be divided into variance originating from all or any part in the 
perceptual process: from differences at receptor and transduction levels (e.g., deficits or genetic differences) to differences in cognitive, emotional and motivational processing. Individual differences in education and results on aptitude tests have, for example, been found to affect the size of the exponent (G. Borg and E. Borg, 1992). Individual variance may, of course, also affect the other constants ( $a$ and $b$, Equation 4), as might, for example, differences in sensory sensitivity.

\subsubsection{Absolute magnitude estimation (AME)}

Many attempts have been made to tackle the problems of individual differences. In all, some assumptions on similarities among individuals are made. In cross-modality matching, subjects are asked to adjust levels of one sensory modality to match various levels of another modality (S. S. Stevens, 1975). One suggestion made by Zwislocki and coworkers is that free magnitude estimation (ME) with a special instruction may meet with the "absolute" demands necessary for interindividual comparisons (AME). The main idea is that through our experience of numerosity, numbers themselves acquire a kind of "absolute" magnitude and will function somewhat like the second modality in cross-modality matching (see, e.g., Hellman and Zwislocki, 1963; Zwislocki and Goodman, 1980; Gescheider, 1997).

\subsubsection{Joint scaling}

In joint scaling, participants scale jointly two (or more) sets of stimulus qualities, in the same session, with regard to a common continuum. Examples are, two different odor qualities. or sounds of different frequencies (Marks, 1974; J. C. Stevens, 1976; B. Berglund, U. Berglund and Lindvall, 1978). Category scaling, magnitude estimation or any other scaling method may be used.

In magnitude matching, participants make magnitude estimations of sets of stimuli on a "common" numerical scale, shifting between two (or more) modalities, for example loudness and brightness, from trial to trial. The rationale is that personal numerical "idiosyncrasies" should be cancelled out of the matching function. Participants serve as their own controls reducing variability in slope, position, and shape of the psychophysical functions. Under the assumption that the psychophysical function of one of the modalities is the same in all individuals, it is possible to assess individual differences in the target modality (J. C. Stevens and Marks, 1980; Marks, G. Borg and Ljunggren, 1983; Marks, 1988). This method has, e.g., been used by Bartoshuk to study sensory differences in taste perception between non-tasters, tasters and super-tasters (see, e.g., Bartoshuk, 2000).

In master scaling, participants use magnitude estimations and scale a set of reference stimuli with known stimulus values jointly with target stimuli, usually of the same modality but for which stimulus intensities need not be known. In order to control for context and individual measurement behavior, individual psychophysical functions for the references are then used for transforming the same individuals' scale values for target stimuli to a master scale. The master scale is defined empirically or postulated and used for calibrating each individual's scale (by a power transformation). The perceived intensities for the different individuals can then be expressed in equivalent perceptual units of the master scale (or in equivalents of the reference function). A joint scaling of references and target stimuli is recommended in order to keep the experimental context constant (B. Berglund, 1991). Master scaling was originally developed for the calibrated measurement of one point on a perceptual continuum (the one target) with the aid of one individual. The method has been used with great success in studies of, e.g., traffic noise, odorous air pollution and in patients with chronic pain (see, e.g., B. Berglund, U. Berglund and Lindvall, 1974; B. Berglund, U. Berglund and Lindberg, 1983; B. 
Berglund and Harju, 2003; B. Berglund, Harju, Kosek and Lindblom, 2002; B. Berglund and Nordin, 1990; Harju, 2002)

\subsubsection{Constrained scaling}

Compared tom Marks and B. Berglund, L. M. Ward takes on a somewhat opposite view on how to treat individual differences, mainly viewed as measurement behavior. He emphasizes the value of "constrained" scaling by using an arbitrary scale. According to this method participants are taught and trained in the use of a certain standard scale with a specific exponent for some chosen modality, until they are able to reproduce the chosen exponent of a psychophysical function with high accuracy. The same persons then use the same scale for scaling perceptual magnitudes of target stimuli. (Ward, 1992, 1997; West, Ward and Kohsla, 2000). A similar approach has also been developed by Fanger (1988) and proposed for applications in the field of indoor air quality (e.g., ECA, 1999).

\subsubsection{Borg's Range Model}

How to deal with individual differences in perceptual scaling was an appealing challenge to G. Borg. He argued that all biological systems have their boundaries, from a minimal to a maximal capacity. According to Borg's Range Model, the total natural, subjective dynamic range from zero (or a minimal intensity) to a maximal or near maximal intensity should be perceptually approximately the same for most individuals. As a consequence any perceived level of intensity can be evaluated in relation to its position in the individual range, and the response for any stimulus intensity can be compared across individuals even when the physical dynamic range varies (see Figure 2). (See G. Borg, 1962, 1990, 1998; Sagal and G. Borg, 1993). Support for this idea was also given by Eisler (1965).

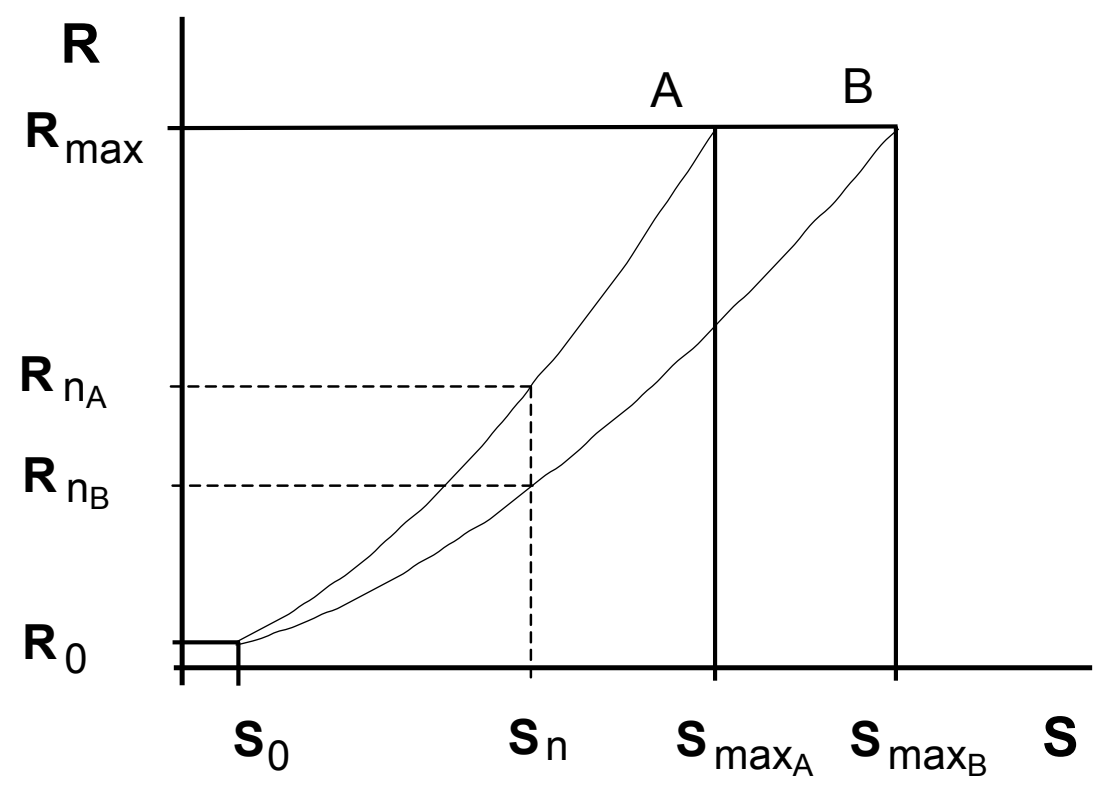

Figure 2. Borg's Range Model. Any sensation or experience will depend upon its position in the natural, subjective, dynamic range. Setting this subjectively approximately equal will enable interindividual comparisons, for example of the responses given by two individuals', A and B. 


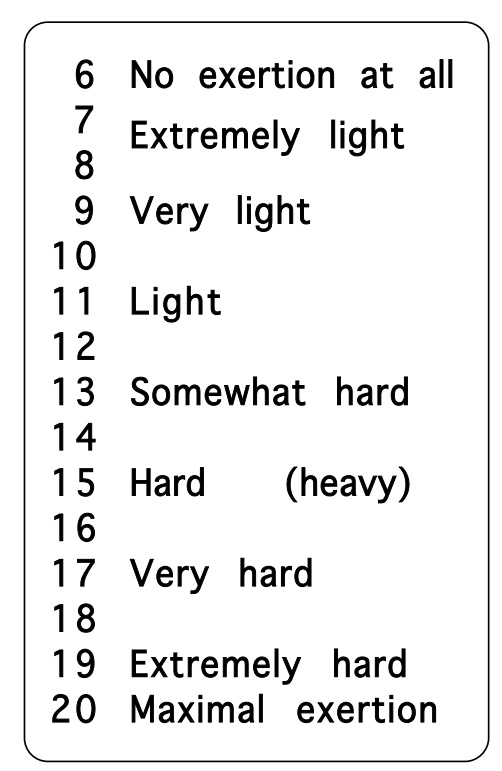

Figure 3. Borg RPE Scale ${ }^{\circledR}$, C Gunnar Borg, 1970, 1985, 1998

\subsection{The Borg RPE scale ${ }^{\circledR}$ and Borg CR10 scale ${ }^{\circledR}$ for perceptual scaling}

Based on the Range Model, a scale for perceived exertion was developed by G. Borg in the 1960'ies, the Ratings of Perceived Exertion (RPE) scale (Figure 3). It was primarily constructed for steady state aerobic work on bicycle ergometer (with stepwise increase of work loads every 4 to $6 \mathrm{~min}$ ). The scale consists of numbers and verbal anchors adjusted to give number responses that increase linearly with stimulus intensity, heart rate (HR in bpm) and oxygen consumption (G. Borg, 1970, 1998). Because of this linearity, the RPE scale can be said to give interval data (with regard to aerobic demands). This is underscored by a choice of a number range from 6 (and not zero!) to 20, corresponding roughly to a HR range of 60 to $200 \mathrm{bpm}$ in healthy people (approx. 30 years of age).

Because of its simplicity the RPE scale has become tremendously popular. The scale is now widely used and recommended in exercise testing, training, rehabilitation, and ergonomics (see, e.g., Borg, 1998; Eston, Lamb, Parfitt and King, 2005; Drury, Atiles, Chaitanya, Lin, Marin, Nasarwanji, Paluszak, Russel, Stone and Sunm, 2006; Dubach, Sixt, and Myers, 2001; Pedersen and Saltin, 2006; Russel, 1997) and has even been translated into Braille (Buckley, Eston and Sim, 2000). There are, however, some major drawbacks with the scale. It does not give power functions in agreement with ratio scaling, and its use in any symptom evaluation is limited.

A process aiming at creating a "level-anchored ratio scale" was begun. It combines the advantages of a ratio scale with those of a labeled category scale. The idea was to place verbal anchors at numerical positions so that ratio data would be obtained. For this to be possible it is of utmost importance with congruence in meaning between the anchors and the numbers on the scale. Building on semantic studies of adjectives and adverbs as multiplicative constants (e.g., Cliff, 1959), several studies in "quantitative semantics" were conducted. In one study, participants were presented to the question "How strong is your feeling of exertion?" together with general expressions commonly used to express an intensity of a perception or a symptom. They were then asked to judge the intensity corresponding to the verbal expression 
on a line from "nothing at all" to "maximal", and also in percent of a maximal intensity. As a frame of reference, participants were instructed to imagine themselves running as much as they could for $15 \mathrm{~min}$ in order to reach maximal exertion. The results showed that it was possible to use adjectives and adverbs to evaluate possible verbal descriptors for positions on a ratio scale (G. Borg, 1962; G. Borg, and Hosman, 1970; Hosman and G. Borg, 1970, G. Borg and Lindblad, 1976).

A parallel way of finding the position for the verbal descriptors was by combining results obtained with magnitude estimation with results obtained with category scales. Ratio scaling, e.g., magnitude estimation, could be used for accurately determining psychophysical functions. Then, the relation obtained between a "symmetrical" category scale (rating scale) and a ratio scale (S. S. Stevens and Galanter, 1957, Eisler, 1962; Eisler and Montgomery, 1974) made it possible to adjust the position of the verbal anchors of the category scale, to obtain a scale that grows linearly with the ratio scale (Figure 4). On such a scale, the verbal label "strong" will have a position of approx. 50\% of "maximal". The result was a "CategoryRatio scale", the Borg CR10 scale, which gave approximately the same psychophysical function as found with magnitude estimation. Based on Borg's Range Model, interindividual comparisons are possible and direct level estimates can be obtained (G. Borg, 1962; 1973b; 1977 ; 1982).

The CR10 has a primary number range from 0 to 10 , with the first verbal anchor at 0.5 . The main anchor is 10, "Extremely strong, maximal". A main anchor should be a stable, schematized conception and may therefore be defined as, e.g., the most strenuous exertion a person has ever experienced previously in his or her life. The scale is, however, continuous with a simple monotonic increase like any other ratio scale, and therefore it has no fixed upper endpoint. This is necessary in order to mimic reality as closely as possible. The advantage with this is obvious, for example, when scaling pain, where the worst pain previously experienced may differ largely from the highest level possible to perceive. Even for other modalities the subjective dynamic range of conceived intensities may not reflect the total range possible to perceive, because of lack of experiences. In the instruction, participants may be encouraged to use decimals, and if necessary numbers below 0.5 as well as above 10 may be allowed. The major range from 0.5 to 10 (1:20) is, however, rather small, and the scale thus gives somewhat low exponents. For practical purposes it is still often good enough.

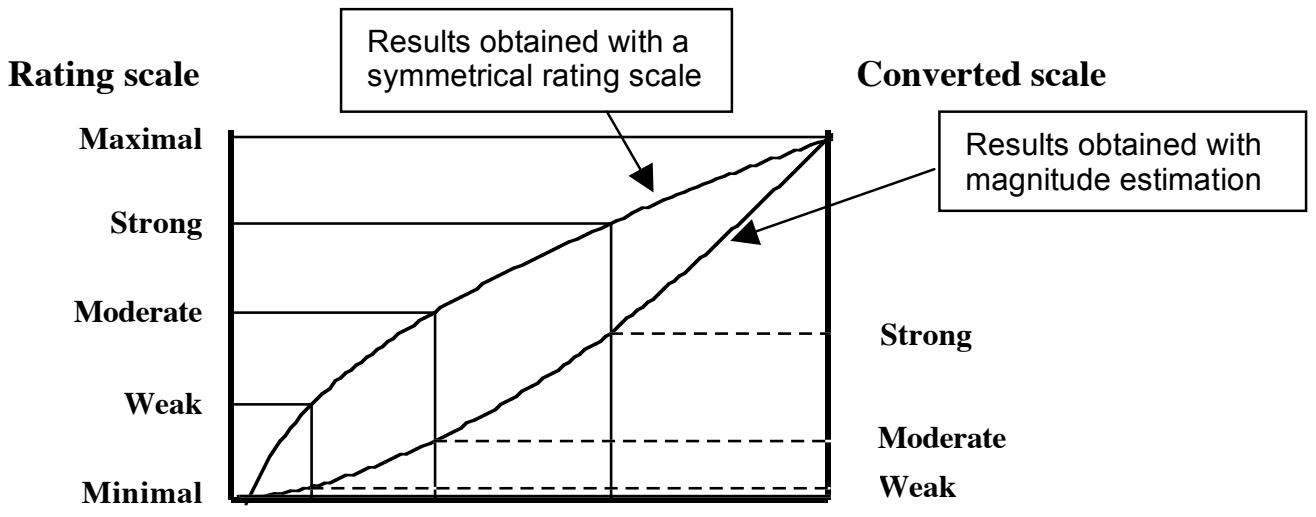

Stimulus intensity, S

Figure 4. Adjusting verbal descriptors to obtain ratio data (adapted from Figure 3, G. Borg and E. Borg 2001). 


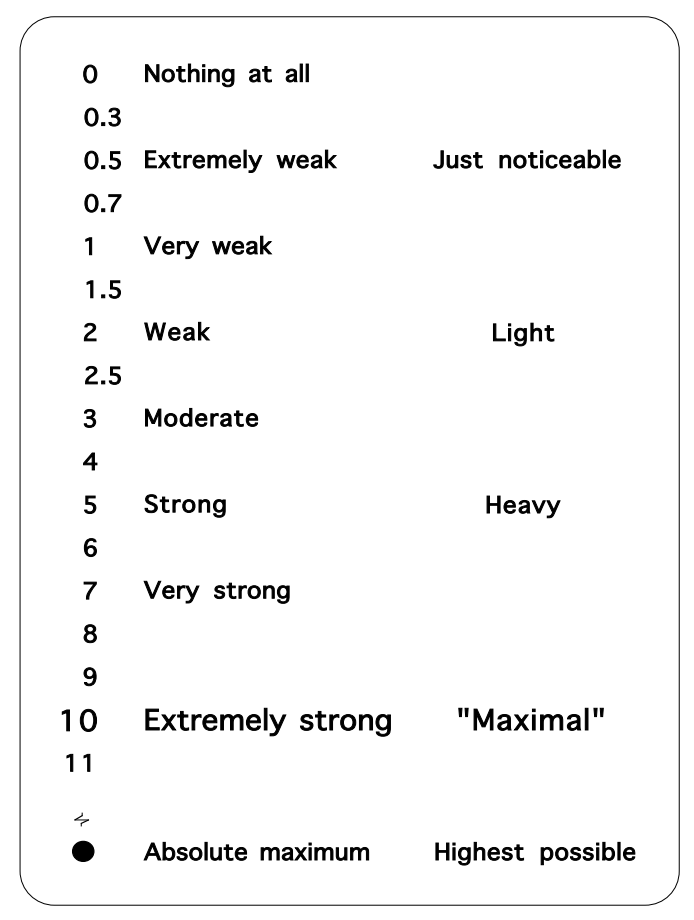

Figure 5. The Borg CR10 scale ${ }^{\circledR,}$ C Gunnar Borg, 1982, 1998, 2003

The reliability and validity of the CR10 scale have been shown in many studies. The scale is a general intensity scale for measurements of most kinds of sensory perceptions, experiences, and feelings. Primarily, however, it has been used in clinical diagnosis of aches and pain, in ergonomy, in determining perceived exertion including "breathlessness", "difficulties breathing", and fatigue, especially in connection with work tests, training, and rehabilitation (see, e.g., G. Borg, 1998; Dedering, Németh, and Harms-Ringdahl, 1999; Geddes, Reid, Crowe, O'Brien and Brooks, 2005; Harms-Ringdahl, 1986; Harms-Ringdahl, Brodin, Eklund, and G. Borg, 1983; Hummel, Läubli, Pozzo, Schenk, Spillmann, and Klipstein, 2005; Mahler and Horowitz, 1994; Mahler, Mejia-Alfaro, Ward and Baird, 2001; Myers, 1994; Ries, 2005; Sjögren, Nissinen, Järvenpää, Ojanen, Vanharanta, and Mälkiä, 2005; Stendardi, Grazzini, Gigliotti, Lotti, and Scano, 2005; Vieira, Kumar, Coury, and Narayan, 2005). But also for taste and odor in elderly, for wine tasting and in treatmens of patients with anorexia nervosa (Bergh, Brodin, Lindberg, and Södersten, 2002; Garriga-Trillo, Muro, and Merino, 2002; Griep, E. Borg, Collys, and Massart, 1998).

\subsection{Other CR scales}

Several other Category Ratio scales have been constructed by G. Borg and collaborators. The purpose has been to increase the number range, to enhance discrimination at low intensity levels, to emphasize the continuous character of the scale, etc. One appealing idea was to use a factorial increase of the positions of the verbal labels, but this gave somewhat high exponents in the psychophysical functions compared to magnitude estimation, and psychophysical functions that were not altogether linear in log-log. The scales were given names depending upon the top numerical anchor, e.g., CR12, CR20 and CR60 (Marks, G. Borg and Ljunggren, 1983; G. Borg, Hassmén, and Lagerström, 1987; G. Borg and E. Borg, 1994). 
Table 1. Summary of general principles behind Category Ratio scales (G. Borg and E. Borg, 2001).

\begin{tabular}{lc}
\hline \multicolumn{2}{c}{ Principle } \\
\hline Definitions & Psychophysiological foundations \\
Target group, most people & Iterative trials, empirically based \\
Competent observers for scale construction & One specific anchor, a "fixed star" \\
Norms obtained separately & The visual design \\
Choice of scale type, preferably ratio & The form of the psychophysical function in \\
The Range Model & agreement with magnitude estimation for several \\
The size of the subjective dynamic range & sensory systems \\
Quantitative semantics & Two-way communication (estimation and \\
Congruence between numbers and anchors & production) \\
Avoiding end effects by open ends & Common psychometric demands \\
Direct method & \\
\hline
\end{tabular}

G. Borg and E. Borg $(1994,2001)$ outlined several general principles and considerations that have governed the construction work of so called Category Ratio scales. A condensed summary is presented in Table 1 .

\subsection{The Borg CR100 (centiMax) scale ${ }^{\circledR}$}

Studies comparing CR scaling with "free magnitude estimation" had shown two important things: First, CR scaling generates psychophysical functions with similar exponents as do magnitude estimation. Second, in contrast to magnitude estimation, CR scaling gives "absolute" intensity-levels (due to the labels) with good possibilities for interindividual comparisons in agreement with Borg's Range Model (see, e.g., G. Borg, Ljunggren, and Marks, 1985; Marks, G. Borg, and Ljunggren, 1983; Neely, Ljunggren, Sylvén, and G. Borg, 1992, G. Borg and E. Borg, 2001). The CR10 scale is, despite its popularity, rather rough and mainly suitable for practical use. Even if the scale is continuous and participants are encouraged to use decimals, they seldom do. This reduces the statistical properties of the data. A more fine-graded scale was desirable.

At an early stage of development percentage ratings were used and 100-graded CR scales were attempted that were not really new scales but mainly equal to 10 times CR10 or 5 times CR20, but these scales never reached outside the laboratory (G. Borg, 1972, G. Borg and E. Borg, 1987, 1994). In the USA, Green also saw the need for a larger numerical range, and building on G. Borg's CR10 scale, constructed a "Labeled Magnitude Scale" from 0 to 100. This scale was, however, mainly intended for taste and odor perception (Green, Shaffer and Gilmore, 1993; Green, Dalton, Cowart, Shaffer, Rankin and Higgins, 1996).

From studies on perceived size, on blackness and on individual measurement behavior, it was concluded that it would be advantageous to incorporate extra clues on the scale, in addition to the verbal labels, to help participants understand the meaning of the verbal labels (G. Borg and E. Borg, 1991, 1992). Thus, triangles increasing in size and blackness congruently with the values of the verbal expressions were chosen. The resulting new CR100 scale is presented 
in Figure 6 (used in Study I of this thesis). The scale starts at a "Minimum" level (1.5), which approximates the absolute threshold. "Maximal, Max X" (100) is anchored in a previously experienced strongest intensity of modality $\mathrm{X}$, often a previously experienced maximal exertion (G. Borg, 1992, 1998). This gives a suitable number range of 1:67, covering the number range of 1:34 reported by R. Theghtsoonian and M. Thegtsoonian (1997) as being the "Range of Acceptable Stimulus Intensity" (RASIN). Because the absolute maximum can be at a level above what is previously experienced, the "Absolute maximum" was marked with a dot and placed outside the given numerical range (similarly as on the CR10 scale). At the bottom of the scale there was also a gap, to emphasize that "nothing at all" is a level very rarely perceived (especially in perceived exertion). The scale was somewhat modified before Study II-IV of this thesis (see also Figure 13).

Since "Maximal, Max X" (100) is the main point of reference, responses are reported in centigrade of this "Max-unit", and the scale may be called a "centi-Max" scale with cM (centi-Max) values. In conformity with this, the CR10 may be called a "deci-Max" scale and the values dM (deci-Max) values (G. Borg and E. Borg, 2001).

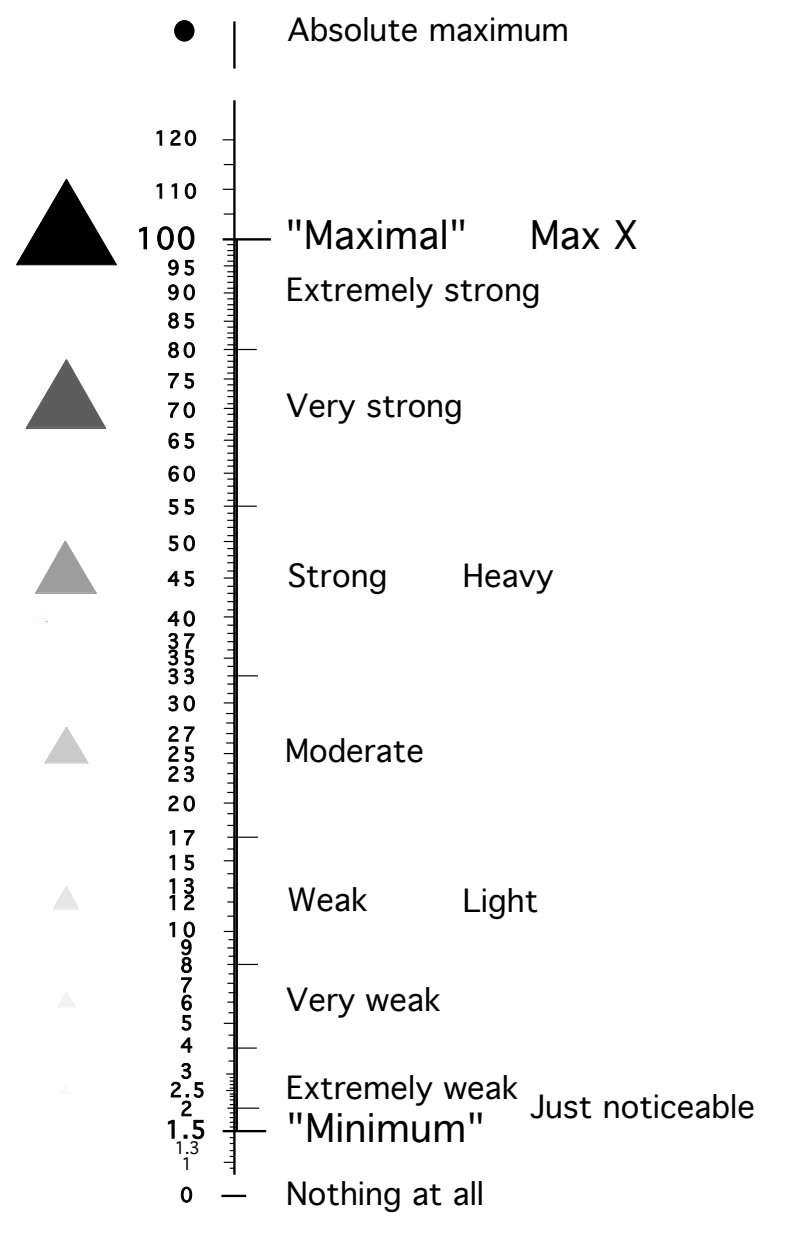

Borg's CR-100 scale
O Gunnar Borg \& Elisabet Borg, 1995

Figure 6. Borg (CR100) centiMax scale (C) G. Borg and E. Borg, 1987, 1994, 1998, 2001, 2002. 


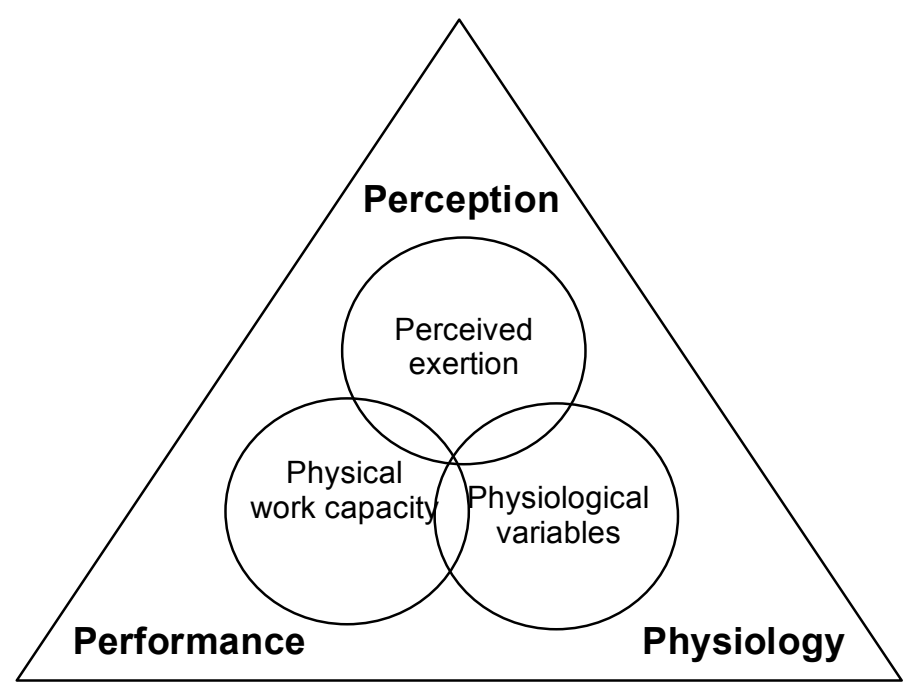

Figure 7. Three effort domains and corresponding continua for physical work.

\section{PERCEIVED EXERTION}

Perceived exertion is somewhat special in that it is the body in interaction with the environment that produces the work perceived as exertion. Several sensory systems are involved conveying information to the brain of how exerted the body is. According to G. Borg (1962) the "overall" perceived exertion should be regarded as a "gestalt" consisting of many cues, "sensations from the organs of circulation and respiration, from the muscles, the skin, the joints, etc" together with perceptions of "pedal resistance, effort, fatigue, strain exertion, heat, pressure, pain or anxiety, etc." Still, overall perceived exertion may be viewed as a unidimensional continuum and its intensity be scaled. Alternatively, it may be viewed as a multidimensional construct of many perceptual qualities.

In dealing with physical work, one need to integrate information from three main effort domains: the perceptual, the performance and the physiological (Borg, 1998). This is illustrated in Figure 7.

\subsection{The perceptual domain}

The overall perceived exertion is built up from many different body symptoms. Cues include those of more peripheral character originating from the skin, moving muscles and joints ("local factors") as well as those of a more central character coming from the cardiopulmonary system ("central factors"). Also psychological states and traits have been found to be of importance (Ekblom and Goldbarg, 1971; Morgan, 1973, 1994; Pandolf, 1978, 1983; Weisser and Stamper, 1977).

Studies in the seventies by Weisser and colleagues resulted in a model, later modified by Pandolf, where "Undifferentiated Fatigue" was suggested to be built up from "Task aversion", "Bicycling fatigue", and "Motivation". Bicycling fatigue in turn consisted of the components "Cardiopulmonary fatigue", "Leg fatigue", and "General fatigue" below which lay the discrete symptoms resulting from reactions in the "Physiological Substrata" (see e.g., Weisser, Kinsman and Stamper, 1973; Weisser and Stamper, 1977 Pandolf, 1983, Pandolf, Billings, Drolet, Pimental, and Sawka, 1984). 
Table 2. Exponents of the psychophysical power function for some different systems (based on Coren, Ward and Enns, 1994; S. S. Stevens, 1975; G. Borg, 1962; G. Borg, Diamant, Ström, and Zotterman, 1967).

\begin{tabular}{lcl}
\hline System & Exponent & Stimulus \\
\hline Brightness & 0.33 & $5^{\circ}$ Target in dark \\
Brightness & 0.5 & Point source \\
Cold & 1.0 & Metal contact on arm \\
Electric shock & 3.5 & Current through fingers \\
Finger span & 1.3 & Thickness of blocks \\
Heaviness & 1.45 & Lifted weights \\
Lightness & 1.2 & Reflectance of gray papers \\
Loudness & 0.67 & Sound pressure of 3000-Hz tone \\
Perceived vocal effort & 1.1 & Vocal sound pressure \\
Perceived exertion & 1.6 & Work on bicycle ergometer \\
Perceived force of handgrip & 1.7 & Precision hand dynamometer \\
Perceived muscle force & 1.7 & Static contractions \\
Smell & 0.6 & Heptane \\
Tactual hardness & 0.8 & Squeezing rubber \\
Tactual roughness & 1.5 & Rubbing emery cloths \\
Taste & 0.66 & Citric acid \\
Taste & 1.3 & Succrose \\
Taste & 1.4 & Salt \\
Visual area & 0.7 & Projected square \\
Visual length & 1.0 & Projected line \\
Warmth & 1.6 & Metal contact on arm \\
\hline
\end{tabular}

G. Borg viewed perceived exertion as unidimensional and studied it with ratio scaling methods (magnitude estimation and ratio estimation). A psychophysical function with an exponent of 1.6 (approx. 1.5-1.7) was obtained for work on bicycle ergometer. The basic constant ( $a$ ) was used in the power function (Eq. 4). It was found to be on average $4 \%$ of the maximal response (G. Borg 1962, 1972). Compared to other sensory systems the exponent is in the same order of magnitude as for example for heaviness, warmth, perceived force of handgrip, and perceived muscle force (Table 2).

\subsection{The physiological domain}

Overall perceived exertion has been shown to have several important physiological correlates. Examples are heart rate (HR), oxygen uptake, carbon dioxide production, pulmonary ventilation, blood lactate $\left[\mathrm{La}^{-}\right]$, blood $\mathrm{pH}$, blood pressure, potassium ions $\left(\mathrm{K}^{+}\right)$, electrical muscle activity as measured by electromyography (EMG), mechanical muscle activity as measured by mechanomyography ( $\mathrm{MMG})$, rectal temperature, and skin temperature. Heart rate is usually regarded as a good correlate for central, cardio-pulmonary factors. Its increase follows the oxygen demands in the muscles and grows approximately linearly with power output for physical work on a bicycle ergometer. Lactate is produced as a natural part of the carbohydrate metabolism and has been suggested to play a major role (even if not directly causal) in "muscle fatigue" and the pain experienced during exercise. It may therefore function as a correlate to perceived muscle activity (see e.g., Åstrand and Rodahl, 1986; 
Pandolf, Billings, Drolet, Pimental, and Sawka, 1984; Miles and Clarkson, 1994; Allen and Westerblad, 2004). In a review by Allen and Westerblad (2004), it is argued that while lactic acid create an extracellular acidosis, that "probably contributes to the painful sensations of "muscle fatigue" experienced by athletes", it also has beneficial effects on the performance of fatigued muscles by affecting important ion channels in the muscle cells. It should be emphasized, however, that causality has yet to be established regarding what physiological mechanisms lie behind the decline in muscle function, as muscles are used intensively and repeatedly.

\subsection{The performance domain}

Physical performance may be measured, for example, as a maximal or peak value obtained under certain circumstances, like the maximum work capacity (Watt) performed in a bicycle ergometer test. Often, physiological correlates are used to measures physical work capacity. One commonly used physiological measure of an individuals' maximal work capacity is maximal oxygen uptake (the volume of oxygen, at standard temperature and pressure extracted from inspired air when performing an exercise test to maximum). The reason is that oxygen uptake is very closely related to the oxygen consumption of the working muscles. Oxygen uptake ( $\dot{\mathrm{V}}_{2}$ ), usually measured in liters per minute, is commonly measured by collecting the expired air during an exercise test with, so called, Douglas bags. It is regarded as a valid and highly reliable measure. The procedure to measure oxygen uptake is, however, somewhat time consuming and the apparatus rather expensive. There are also difficulties involved when stressing participants to their absolute maximum.

Since there is a linear relationship between oxygen uptake and heart rate, individual work capacity can also be assessed from heart rates. According to the methods suggested by Sjöstrand (1947) and Wahlund (1948), individual work capacity may be expressed as the estimated power level in Watt on the bicycle ergometer for a certain heart rate, e.g. 150 or 170 beats/minute $\left(\mathrm{W}_{150}\right.$ or $\left.\mathrm{W}_{170}\right)$ (cf. Åstrand and Rodahl, 1986).

Perceptual measures can also be used to estimate work capacity. If a person is exercising at approximately $80 \%$ of his/her work capacity a response of " 17 " is commonly obtained on the RPE scale (Figure 3). The estimated work capacity in Watt for this exercise level would then be denoted $\mathrm{W}_{\mathrm{R} 17}$ (Borg, 1998).

\section{AIM OF THE THESIS}

The aim of the thesis was to explore general and differential aspects of perceived exertion as well as to measure perceived exertion. Perceptual measures of the new improved Borg CR100 (centiMax) scale was compared with magnitude estimation, and with the classical Borg CR10 and RPE scales. Perceptual measures were also compared with physiological ones as well as with physical performance for direct level estimates and individual differences. Multidimensional components of perceived exertion, symptoms occurring as a result of physical work in healthy people were measured, both for work on bicycle ergometer and for conceptualized daily activities and exercise/sports activities (Figure 8). 


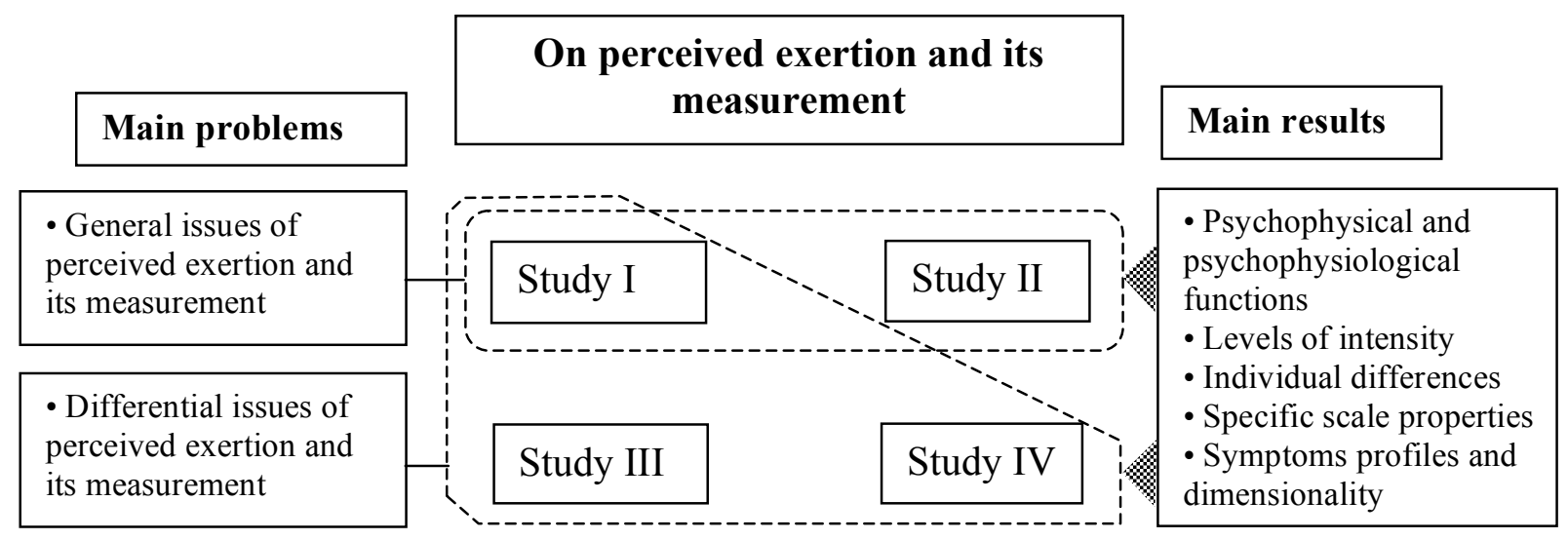

Figure 8. Schematic illustration of the content of the thesis.

Specifically the following problems were addressed:

(a) General and individual psychophysical functions (Study I and Study II).

(b) Interindividual comparisons and direct level estimates (Study I and Study III).

(c) Borg's Range Model, enhancing assessments of individual differences (Study I, Study III and Study IV)

(d) Perceived exertion in daily activities and sports activities (Study IV).

(e) The multidimensional character of perceived exertion (Study III and Study IV).

\section{SUMMARY OF THE STUDIES}

Four empirical studies were conducted and integrated in this thesis:

Study I Borg, E., and Borg, G. (2002). A comparison of AME and CR100 for scaling perceived exertion. Acta Psychologica, 109, 157-175.

Study II Borg, E., and Kaijser, L (2006). A comparison between three rating scales for perceived exertion and two different work tests. Scandinavian Journal of Medicine in Science and Sports, 16, 57-69.

Study III Borg, E. (manuscript). Individual differences in perceived exertion assessed with the Borg RPE, CR10, and CR100 scales.

Study IV Borg, E. (manuscript). Interindividual assessment of multidimensional symptoms of perceived exertion.

\subsection{A comparison of AME and CR100 for scaling perceived exertion (Study I)}

The aim of this study was to compare the new CR100 scale with AME (Absolute Magnitude Estimation). Both methods claim to give directly interpretable responses on a ratio scale enabling calculations of psychophysical growth functions. They also claim to deliver separate levels of intensity that permit interindividual comparisons without any transformation of data. Perceived exertion on a bicycle ergometer was used for scale comparisons. It is easily administered and has the advantage of concomitant physiological correlates. In study I heart rate (HR) was chosen as physiological correlate.

In all, thirty-two participants (as many men as women) took part in two sessions, one for each 
scale. Half of the group started with AME, the other with CR100. A bicycle ergometer test was used with 3-min exercise at each load and a stepwise increase of $30 \mathrm{~W}$ to voluntary maximum. Towards the end of each stimulus level, participants gave their perceived exertion responses and HR was recorded.

\subsubsection{Psychophysical and psychophysiological function}

Perceived exertion with AME as well as with CR100 could be described according to Equation 4 (section 2.2 above):

$$
\mathrm{R}=a+c(\mathrm{~S}-b)^{\mathrm{n}}
$$

The basic constant $(a)$ was set to ca. $4 \%$ of the maximal response range, and the constant $(b)$ was equal to zero. Depending on number or data points used (participants stopped at different levels because of differences in individual work capacity), the exponents based on group data were for AME between 1.4 and 1.7 and for CR100 between 1.6 and 1.7. Correlations between $\log$ scale-values $(\log (\mathrm{R}-a)$ for AME and CR100) and $\log \mathrm{S}$ (Watt) were above 0.99. HR was linearly regressed against $S$ (Watt) and the correlations were above 0.99 , with steeper functions for women than for men.

\subsubsection{Individual differences and separate levels of intensity}

It was also found that whereas CR100 could discriminate perceived exertion between men and women and their different physical work capacity, AME could not (as judged from correlations with HR). When AME-data was corrected according to the Range Model, a moderate correlation was, however, obtained for the total group, but not for men and women separately. An ANOVA showed significant differences in HR between men and women, as well as a significant interaction effect, Stimulus level x Gender (synergistic, corresponding to the slope difference in $H R=f(S)$ ). The same effects were obtained for CR100 responses, but not for AME responses. For AME, instead, scale order (participants started with CR100 or with AME), significantly affected the responses.

Work capacity, estimated from CR100 at $50 \mathrm{cM}$ (WR50), was significantly different for men and women, and approximately the same difference was obtained as for the corresponding HR-estimate (W150). This was not the case for AME.

\subsubsection{Specific scale properties}

CR100 also showed less variability than the AME (approx. 1/3) across participants for each stimulus level as measured by the coefficient of variation, even if the variability was not as low as for HR. This means a higher agreement in numbers chosen for CR100 than for AME.

\subsubsection{General conclusions}

Data obtained with CR100 was thus concluded to function as well as AME with regard to psychophysical functions and ratio data. For assessing individual differences, CR100, however, proved superior.

\subsection{A comparison between three rating scales for perceived exertion and two different work tests (Study II)}

The purpose of this study was manifold. The first aim was to investigate differences between two bicycle ergometer work tests commonly used clinically. Secondly, and of most interest to 
this thesis, the aim was to compare the Borg RPE, CR10 and CR100 scales. Comparisons were also made to two physiological variables, heart rates and blood lactates. A third aim was to describe the growth function for blood lactate.

Two studies, one for each work test, were carried out. In Study 1, the bicycle ergometer work test was run with an increase in power every minute, starting at $20 \mathrm{~W}$ and increasing with 20 $\mathrm{W}$ for the 24 men and with $15 \mathrm{~W}$ for the 16 women. A between-subjects design was used, with one group of 12 men and 8 women using the CR10 scale, and one equally large group using the RPE scale. HR was measured every minute and [ $\left.\mathrm{La}^{-}\right]$every third minute. In Study 2, a $25 \mathrm{~W}$ increase every third minute (starting with $25 \mathrm{~W}$ ) was used for the 12 men as well as for the 12 women. A within-subjects design was used. Half of the participants started with the CR10 scale on the first occasion and with the RPE and CR100 scales at the second occasion.

\subsubsection{Psychophysical and psychophysiological functions}

Individual psychophysical functions were calculated for all participants. For the RPE scale, linear regression equations were used since the RPE scale is constructed to give a linear increase with an increase in work laod. For the CR scales, power functions (Eq. 4) were appropriate. For the RPE scale, steeper functions were obtained for women (mean slope 0.066) than for men (mean slope 0.039 and 0.049). Average exponents obtained with the CR10 was 1.1 for women and 1.3 for men in Study 1, and 1.5 for women and 1.4 for men in Study 2. With the CR100 (Study 2) exponents were 1.5 for women and 1.2 for men. Best fit correlations were on average above 0.97. Differences in exponents between men and women were not significant. For HR, linear regressions were calculated with steeper functions for women than for men and correlations were ca. 0.99. For [ $\left.\mathrm{La}^{-}\right]$in Study 1, Eq. 4 with both basic constants ( $a$ and $b$ ) was used and exponents were roughly found to be between 2.4 and 2.9, and correlations of approx. 0.98 .

With the work test used in Study 1 (1 min on each load), significantly lower exponents were, on average, obtained with the CR10 scale, than what has commonly been obtained for work tests with several minutes on each load (where an exponent of at least $n=1.5$ is usually obtained). Exponents obtained with the CR10 in Study 1 were also significantly lower compared to those obtained in Study 2 where $3 \mathrm{~min}$ on each load was applied. There was no significant difference in exponents between the CR10 and CR100 scales, confirming that the scales worked in a similar way.

\subsubsection{Specific scale properties}

On the CR100, a larger number range is available and the differences in actual number ranges used were 1.3 times larger with the CR100 scale than with the CR10 scale. The difference was, however, non-significant. A comparison between the scales also showed that the tendency of using primarily numbers at the exact locations of the verbal anchors was a little less with the CR100 scale than with the CR10 scale. The CR100 thus satisfies the claim of being more fine-graded than the CR10.

\subsection{Individual differences in perceived exertion assessed with the Borg RPE, CR10 and CR100 scales (Study III)}

The purpose of Study III was to compare the commonly used scaling methods for perceived exertion, the Borg RPE, CR10 and CR100 scales, with regard to differential aspects of the psychophysical functions as well as regarding separate levels of intensities. Validity of individual differences was assessed by the physiological correlates heart rate (HR) and blood 
lactate $\left[\mathrm{La}^{-}\right]$, and by comparisons of estimates of work capacity obtained from psychological and physiological measures. Reliability was assessed by split-half, parallel test and test-retest correlations. Individual CR10 responses were compared to individual responses in HR and [La']. Study III included further analysis of the data collected in Study II.

\subsubsection{Psychophysical and psychophysiological functions}

Significant slope differences between men and women were obtained for HR functions and for the RPE scale, men giving lower slopes than women. Individual power functions (Eq. 4) with individual values of the one basic constant $(a)$, and the other $(b)$ equal to zero) were calculated for CR-data. No significant differences between men and women were found for exponents (n) or measure constants (c). In Study 2 the correlation between individual exponents, $\mathrm{n}_{\mathrm{CR} 10}$ and $\mathrm{n}_{\mathrm{CR} 100}$, was $\mathrm{r}=0.466(\mathrm{p}=0.0207)$ and between individual measure constants, $\mathrm{c}_{\mathrm{CR} 10}$ and $\mathrm{c}_{\mathrm{CR} 100}, \mathrm{r}=0.601(\mathrm{p}=0.0015)$.

\subsubsection{Individual differences and direct levels of intensity}

When G. Borg's range model was applied, it was found that for most participants' ratings with the CR10 scale followed one or the other of the physiological variables, and only for two participants was it true that CR10 values fell on a curve between $\mathrm{HR}$ and [ $\left.\mathrm{La}^{-}\right]$.

Several significant, moderate to high correlations were obtained between perceived exertion and physiological scale responses at each power level on the bicycle ergometer ( 0.4 to 0.8$)$ for the total group. Correlations were higher for women than for men. If, for Study 2, the five levels in common to all participants were used, very strong and significant correlations between 0.7 and 0.9 were obtained between perceived exertion and HR. In order to let each participant be represented by only one data point, the 24 participants were randomly assigned to one of these five levels (drawn without replacement). This was done five times and correlations of between 0.75 and $0.89(\mathrm{p}<0.001)$ were obtained.

Before participants entered into the exercise test, reports of their physical fitness were obtained on a 13-point interval scale. Correlations between self-reported physical fitness (PF), scale responses of perceived exertion and physiological variables, were significant and moderate to strong $(-0.28$ to -0.65$)$. Four groups were then created based on self-reported physical fitness (PF): Weak women; Strong women; Weak men; and Strong men. Post hoc tests, following one-way ANOVAs, showed that there were significant pair-wise differences between most groups (even in one case between Weak men and Strong women). There were some more group differences for physiological variables.

Significant differences between men and women in work capacity, $\mathrm{W}_{170}$ (a commonly used estimate of individual work capacity derived from linear regressions between HR and power) were obtained. For each psychophysical scale, a measure corresponding to $\mathrm{W}_{170}$ can be estimated from individual psychophysical functions: estimated work capacity from RPE data $(\mathrm{RPE}=17), \mathrm{W}_{\mathrm{R} 17}$, estimated work capacity from $\mathrm{CR} 10$ data $(\mathrm{CR} 10=7), \mathrm{W}_{\mathrm{R} 7}$, and estimated work capacity from CR100 data $(\mathrm{CR} 100=70), \mathrm{W}_{\mathrm{R} 70}$. High and significant correlations with $\mathrm{W}_{170}$, between 0.75 and 0.95 were obtained for women, but for men only a few significant correlations above 0.5 were obtained. Also, only small differences of between 2 and $38 \mathrm{~W}$ were found between mean values of $\mathrm{W}_{\mathrm{R} 17}, \mathrm{~W}_{\mathrm{R} 7}, \mathrm{~W}_{\mathrm{R} 70}$, and $\mathrm{W}_{170}$. Thus, a high degree of level accuracy was obtained.

In Study 1, a comparison was possible between estimated "peak"-values of work capacity $\left(\mathrm{W}_{\mathrm{R} 19}, \mathrm{~W}_{\mathrm{R} 9}\right)$ and the terminal work level actually performed $\left(\mathrm{W}_{\max }\right)$ on the bicycle ergometer. 
Very high and significant correlations were obtained of approx. 0.9. Correlations between $\mathrm{W}_{\mathrm{R} 19}$ or $\mathrm{W}_{\mathrm{R} 9}$ and $\mathrm{W}_{\mathrm{HRmax}}$ were between 0.7 and 0.8 . Predictions obtained with the scales $\left(\mathrm{W}_{\mathrm{R} 19}, \mathrm{~W}_{\mathrm{R} 9}\right)$ differed from $\mathrm{W}_{\max }$ by only a few Watt and were not significant. Accuracy of both level estimates and of individual differences was thus further supported.

\subsubsection{Specific scale properties}

When corrected for attenuation ${ }^{1}$, split-half correlations for slopes of RPE functions and exponents of CR-functions were found to be between 0.82 and 0.99 with the lowest correlations for the RPE scale. Despite their differences, the RPE and the CR10 scales may be regarded as parallel tests of perceived exertion. At $120 \mathrm{~W}$ (where both scales were used by all participants in Study 1), a correlation $\mathrm{r}_{\mathrm{RPE}, \mathrm{CR} 10}=0.869(\mathrm{p}<0.0001)$ was obtained. In Study 2 all participants used all three scales. The RPE and CR100 scales were used on the same occasion but the CR10 scale was used with 2-3 weeks separation and can thus also be regarded as giving a kind of retest reliability. The following correlations were obtained over the five work levels on the bicycle ergometer in common to all but one participant (whose values at the fifth level were extrapolated): $\mathrm{r}_{\mathrm{RPE}, \mathrm{CR} 100}=0.923 ; \mathrm{r}_{\mathrm{RPE}, \mathrm{CR} 10}=0.838$; and $\mathrm{r}_{\mathrm{CR} 100 \text {, }}$ $\mathrm{CR} 10=0.840$. All correlations were significant $(\mathrm{p}<0.0001)$.

\subsection{Interindividual assessment of multidimensional symptoms of perceived exertion (Study IV)}

The main purpose was to study the multidimensional character of perceived exertion by means of a questionnaire with the Borg CR100 (centiMax) scale. As test items, 41 daily activities and sports activities were used to investigate 18 symptoms associated with physical exertion. The symptoms were "overall exertion"; "breathlessness"; "difficulties breathing"; "heart pounding"; "chest pain"; "joint soreness"; "joint pain"; "leg muscle fatigue"; "leg muscle soreness"; "leg muscle pain"; "exhaustion"; "sweating"; "ear buzzing"; "headache"; "feeling sick"; "discomfort"; "aversion"; and "revived". Sixty-four healthy volunteers (36 men and 28 women) participated in the questionnaire study. A sub-group of 40 of these (24 men and 16 women) measured the perceived intensity of the symptoms with the CR10 scale after work on a bicycle to voluntary maximum, as well as after work at a sub-maximal level $(120 \mathrm{~W})$. After the work tests heart rate $(\mathrm{HR})$ and blood lactate [La'] were measured. (Study II and III report in detail data from the work tests).

\subsubsection{Individual differences and direct levels of intensity}

Women gave significantly higher perceived levels of intensity than men for symptoms, especially for activities of low to moderate intensity. The interpretation was thus that women work harder than men do in ordinary daily activities and sports activities of rather low intensity levels. For the sub-group of 40 participants, who answered the questionnaire as well as performed the bicycle ergometer work test, significant correlations of approx. 0.3-0.5 were obtained between heart rate and perceived intensity of several symptoms for one specific activity ("Carrying a sofa up 3 stairs, 2 persons"). This showed that individual differences obtained with the questionnaire to be both valid and reliable. This also supported the validity of using the CR100 scale in the questionnaire.

\subsubsection{Symptoms profiles and dimensionaltiy}

Symptoms profiles were similar for different intensity levels, both for the questionnaire data and for the bicycle ergometer data. Significant interaction effects were obtained between

${ }^{1} \mathrm{r}=\left(2 \mathrm{r}_{1 / 2}\right) /\left(1+\mathrm{r}_{1 / 2}\right)$ 
symptoms and activities indicating that some activities, for example, rely more on respiration than on working muscles, or vice versa. For the questionnaire as well as for the sub-maximal work test, factor analyses of symptoms profiles showed that the dominating symptoms in perceived exertion were "breathlessness", "heart pounding", "overall exertion", "sweating", "muscle fatigue", and "exhaustion". For the work test to voluntary maximum, two exertion factors were extracted, one for more local/ peripheral symptoms ("leg muscle fatigue", "exhaustion" and "sweating") and the other for more central sensations of exertion ("overall exertion", "breathlessness", and "heart pounding").

In a clinical setting when patients work on a bicycle ergometer it is not possible to measure as many as 18 symptoms as in this study. However, a questionnaire can be used as a screening instrument combined with two or three symptoms which can be selected for the work test.

\section{DISCUSSION}

\subsection{General and individual psychophysical functions (Study I and Study II).}

Both the CR100 and the AME methods are claimed to give directly interpretable responses on a ratio scale enabling calculations of psychophysical growth functions. In Study I of this thesis (E. Borg and G. Borg, 2002), a comparison of the CR100 was made to the perceptual scaling method of AME on perceived exertion (Hellman and Zwislocki, 1961; Zwislocki and Goodman, 1980). An assumption was that AME does give ratio data for perceived exertion and other perceptions and that the CR100 scale would do so equally well.

Both AME and CR100 results could be well described by power functions with exponents that were very similar. It can thus be concluded that to the extent that absolute magnitude estimation gives ratio data, CR100 does so as well (see Figure 9). This is in agreement with what has previously been observed for the Borg CR10 scale and for previous versions of more fine-graded CR scales, when compared with magnitude estimation on various modalities (G. Borg and E. Borg, 1994; 2001; G. Borg, 1998).

Since the CR10 scale is widely used in practice, especially for scaling pain and dyspnea, comparisons were made between the CR100 and CR10 scales in Study II (E. Borg and Kaijser, 2005). No significant differences in exponents were found between the CR10 and CR100 scales. This confirms that the scales work in a similar way with regard to scale/data level. A tendency to use primarily numbers at the exact locations of the verbal anchors was a little less with the CR100 scale than with the CR10 scale. Thus, the CR100 fulfills the claim of being more fine-graded than the CR10. The number range actually used on the CR100 was also on average approximately 1.3 times larger than the one used on the CR10 scale (though this difference was not found to be significant). 


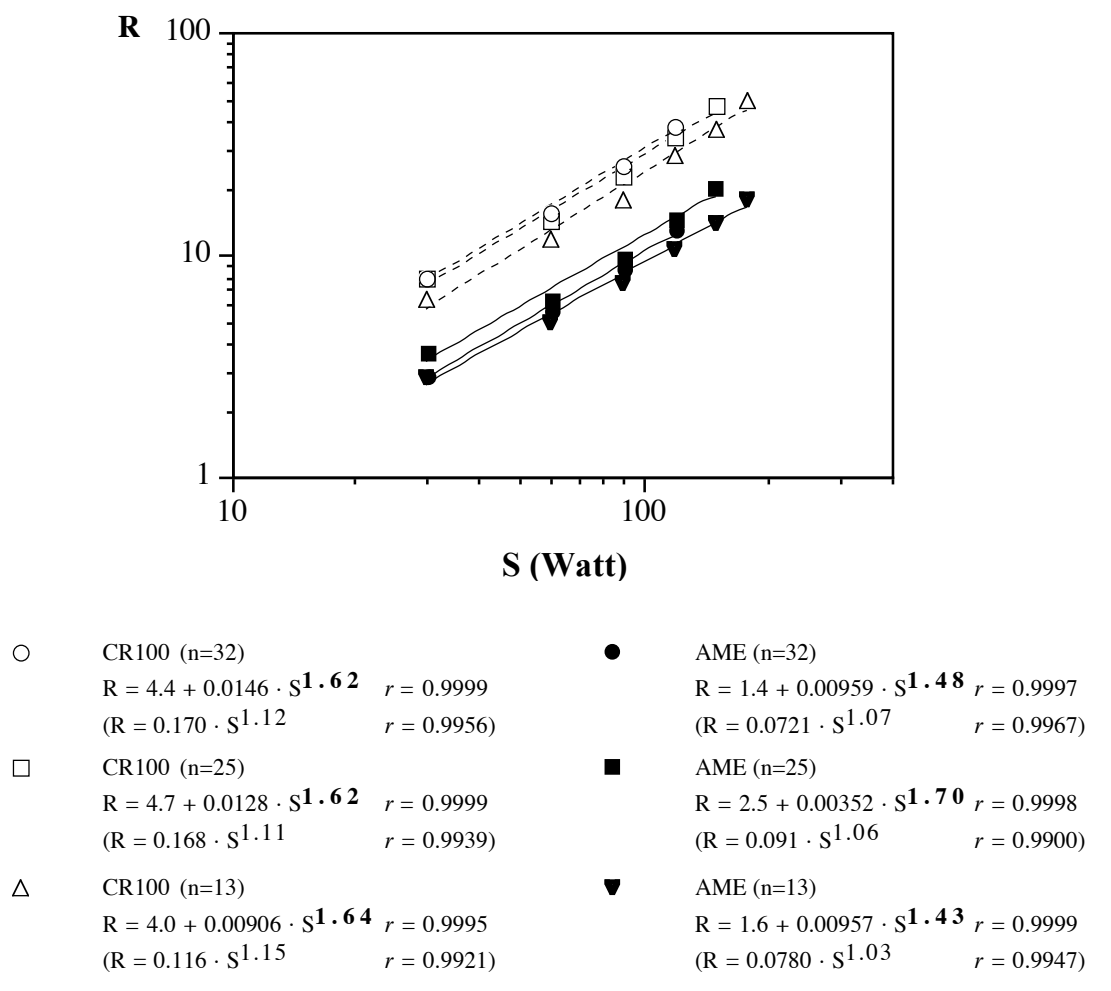

Figure 9. Psychophysical functions of perceived exertion with AME and CR100 as a function of workload (Watt) based on group data with four $(n=32)$, five $(n=25)$ and six (n $=13$ ) data points (Figure 2 in Study I). Reprinted with permission from Elsevier.

\subsection{Interindividual comparisons and direct level estimates (Study I, Study III and Study IV).}

The CR100 and the AME methods are both also claimed to give separate levels of "absolute" intensity. This permits interindividual comparisons without any transformation of data. In Study I of this thesis (E. Borg and G. Borg, 2002) a comparison of the CR100 was made to the perceptual scaling method of AME (Hellman and Zwislocki, 1961; Zwislocki and Goodman, 1980) with the assumption that while CR100 would work for interindividual comparisons, AME would not.

Correlations of above 0.6 were obtained between HR and perceived exertion responses on the CR100 scale at the workloads of $90 \mathrm{~W}$ and $120 \mathrm{~W}$ on the bicycle ergometer (Study I). Participants with lower physical work capacity gave higher numbers on the scale because of their higher degree of perceived exertion. No such correlations were found for AME. Thus, in contrast to CR100, AME does not give separate levels of "absolute" intensity.

Work capacity, estimated from $\mathrm{HR}$ at 150 beats/min, $\mathrm{W}_{150}$, was significantly different for men (on average $175 \mathrm{~W}$ ) and women (on average $128 \mathrm{~W}$ ). A similar and significant difference was also obtained as for the corresponding CR100-estimates at $50 \mathrm{cM}, \mathrm{W}_{\mathrm{R} 50}$ (on average $168 \mathrm{~W}$ for men and $136 \mathrm{~W}$ for women). This was not the case for AME. CR100 also showed less variability across participants for each stimulus level as measured by the coefficient of 
variation, than did AME (approx. 1/3), even if the variability was not as low as for HR. This shows a higher agreement on chosen numbers for CR100 than for AME. Thus, it may be concluded that whereas CR100 works well as an "absolute" method for direct level estimates, AME does not. The latter is also in agreement with what has been found by B. Berglund (1991).

Comparisons were also made between the Borg RPE, CR10 and scales. In Study III individual comparisons of perceived exertion were made with the aid of two of its physiological correlates, i.e., HR and [ $\left.\mathrm{La}^{-}\right]$(blood lactate). An ANOVA showed that the three psychophysical scales could, almost as well as the two physiological scales, differentiate the four groups: Strong men, Weak men, Strong women, and Weak women (groups were based on self-reported physical fitness on a 13-point interval scale; G. Borg, Skinner, and Bar-Or, 1972). Conclusions were further confirmed by correlations between scale values of perceived exertion and physiological scales ( $\mathrm{HR}$ and $\left[\mathrm{La}^{-}\right]$), as well as by correlations among the different estimates of work capacity $\left(\mathrm{W}_{\mathrm{R} 17}, \mathrm{~W}_{\mathrm{R} 7}, \mathrm{~W}_{\mathrm{R} 70}\right.$, and $\left.\mathrm{W}_{170}\right)$. These results are congruent with those previously reported for the Borg CR10 scale (Marks, G. Borg and Ljunggren, 1983; Marks, Borg and Westerlund, 1992).

\subsubsection{For multidimensional symptoms of perceived exertion}

As expected, gender differences were found to be significant for "overall exertion" and several other symptoms for activity A23 ("Carrying a sofa up 3 stairs, 2 persons") of the questionnaire, as well as for the sub-maximal bicycle ergometer test (Study IV). Somewhat unexpectedly, however, women's scale values were significantly higher for many symptoms of several other activities as well (further discussed in section 6.4.)

An interesting finding was also the rather strong and significant correlation $(\mathrm{r}=0.53)$ between individual heart rates obtained after the sub-maximal test and the individual measures of "overall exertion" for A23 ("Carry a sofa..."). An interindividual correlation between heart rate, when actually riding a bicycle, and a judgment of the idea (conception) of the "overall exertion" in "carrying a sofa up 3 stairs, 2 persons", done at two separate occasions is actually very good. That there was no correlation between heart rate and the symptom "revived" $(\mathrm{r} \leq$ 0.1 ) shows that participants with less physical fitness did not just give higher scale values in general for all symptoms. These results strengthen the value of the CR100 for interindividual comparisons and direct level estimates as well as adds to the discriminative validity of the questionnaire.

\subsubsection{Prediction of gender and physical fitness}

Data from Study I, and Study III, was reanalyzed by logistic regression to study how well perceived exertion data with the RPE and CR scales, and HR data, function as predictors for gender. The results are presented in Table 1 and 2 of Appendix of this thesis. A few cases with z-residuals above 2.5 were found. They were all found either in the group of Weak men or of Strong women.

As can be seen from Table 1 of the Appendix, all predictor variables but AME were significant $\left(\chi_{1}^{2}>8, p<0.01\right)$. It is interesting to observe from the PAC (overall percentage accuracy in classification) that CR and RPE scale values predicted gender equally well as did HR (between $75 \%$ to $90 \%$ accuracy of prediction). Study III:1 with the largest number of participants, also had the highest PAC. Table 2 of the appendix gives the obtained logistic regression equations with significant regression coefficients (as judged by Wald values) for all predictors except for $\mathrm{AME}$ responses. The $\operatorname{Exp}(\mathrm{B})$ is the odds ratio, i.e. the increase in 
odds of being a woman when the value of the predictor (RPE, CR or HR) increases by one unit.

Obviously one would not expect accuracy in classification at $100 \%$, since there is an overlap in physical work capacity between men and women. The strongest women were at least equally strong as the weakest men. A further study of misclassified participants was therefore performed. All studies considered, 35 out of 96 participants were misclassified by at least one method (AME excluded). Of these, 4 were Weak women, 12 were Strong women, 17 were Weak men, and 2 were Strong men (by their own account, i.e. based on their self-reported physical fitness values on a 13-point interval scale; G. Borg, Skinner and Bar-OR, 1972). This relationship between strength and gender for the misclassified cases was found to be significant, $\chi_{1}^{2}=15.0(\mathrm{p}<0.001)$, and thus explains most of the misclassifications.

The more interesting misclassifications were then the 4 Weak women classified as men, and the 2 Strong men classified as women. A closer look on their data showed that one of the Weak women had a self-reported physical fitness value of 7 and was classified as a man only by transformed AME responses and not by HR values or CR100 responses. The second woman also had a self-reported physical fitness value of 7 and was misclassified by HR but not by scale responses. The third woman had a self-reported physical fitness value of 5 , and was also misclassified only by HR. Those two might either have had a lower than average maximal heart rate or were just not as weak as they thought themselves to be. The fourth woman, also with a self-reported physical fitness value of 5, was, however, misclassified only by scale responses and not by HR. A further look at her data showed that she was one of 6 (of a total of 16 women in Study III:1) who could continue as far as to a workload of $225 \mathrm{~W}$ before she had to quit bicycling and was thus actually a rather strong woman. The first of the two Strong men who were classified as women, had a self-reported physical fitness value of 9, and was misclassified by scale responses but not by HR. He was, however, one of 7 (of a total of 16 men in Study I) who did not continue further than to the workloads 150 and $180 \mathrm{~W}$ on the bicycle ergometer, and was thus actually rather on the weaker side of the group of men. The other one with a self-reported physical fitness value of 10, a participant in Study III:2, was misclassified only by CR100 responses. Looking at his data there were no obvious reason why this should be the case. In the regression equation in Table 2, however, the probability obtained was only 0.502 that he would be a woman $(0.5$ being the $50 \%$ probability cut-off point). This new analysis further strengthens the conclusion that judgments with the Borg RPE and CR-scales are valid instruments for assessing individual differences.

\subsection{Borg's Range Model, enhancing assessments of individual differences (Study I, Study III and Study IV)}

According to the Range Model, each individual's response may be evaluated with regard to its position in the subjective dynamic range (cf. Figure 2). This is one of the main assumptions behind the CR methodology. In Study I individual's worked on the bicycle ergometer until a voluntary maximum (a level close to the maximal level) was reached. The response at this terminal level could be called $\mathrm{R}_{\mathrm{t}}$. When a correction of AME-data according to the Range Model was done, by multiplying each individual rating with $100 / \mathrm{R}_{\mathrm{t}}$, a moderately strong correlation with HR was obtained for the total group of men and women (at $120 \mathrm{~W}$ ). 
Data from Study I was reanalyzed by logistic regression (see above 6.2). The results showed that corrected AME-data worked equally well as HR and CR100 as predictor variable for gender (see Table 1 of the appendix).

In Study III, where ratings as well as two physiological variables were measured at several occasions throughout the work test, the Range Model was applied to individual data. Graphs then showed participants' response patterns to vary. For only 2 participants the CR responses fell on a curve in-between HR and [ $\left.\mathrm{La}^{-}\right]$. For most (15) participants, scale responses followed more closely the growth of either of the physiological variables, and for 3 individuals the response pattern either was hard to interpret or changed during the work test.

According to the Range Model, the perception of symptoms will carry a high degree of similarity at maximal levels. In Study IV, 18 discrete symptoms associated with exertion were measured with the CR100 scale in a questionnaire with daily activities and sports activities of different intensity, as well as after a sub-maximal work test of 6 min at $120 \mathrm{~W}$ and at the end of the max test described in study II (E. Borg and Kaijser, 2005). While a significant effect of gender was obtained at the sub-maximal level, with women reporting a significantly higher perceived exertion, no difference between men and women was obtained at the maximal level. The same was true for the questionnaire: women's scale responses were significantly higher than men's for activities of low intensity, but not for more physically demanding activities.

Taken together, this shows Borg's Range Model to be a valuable way to enable assessments of individual differences (cf. Sagal and G. Borg, 1993).

\subsection{Perceived exertion in daily activities and sports activities (Study IV).}

In the questionnaire of Study IV, 41 daily activities and sports activities with a large variation in natural levels of intensity were used as stimuli. Doubly multivariate ANOVAs did, not surprisingly, show significant main effects for differences between activities. Gender differences were à priori expected for one of the activities, A23 ("Carry a sofa up 3 stairs, 2 persons"), but significant gender differences were found for other activities as well (Figure $10)$.

Doubly multivariate ANOVAs also showed significant effects for gender especially for activities of lower levels of intensity. If women are as true to their bodily state as men are when they report their perceptions, an explanation for this may be that women, having to adapt to a world of masculine dominance, actually exert themselves a little more than men do, especially at low to moderate intensity levels. Research in other areas has shown that women appear to be more attentive than men to their internal state when reporting symptoms (e.g., Pennebaker, 1982). This may, however, apply to a higher degree of accuracy and discrimination rather than to higher intensity reports.

Significant interaction effects between symptoms and activities were also found. Some activities rely, as an example, more on respiration than on working muscles, other activities take more muscle strength than aerobic capacity. That this is reflected by the subjective reports also contribute to the content validity of the questionnaire. 


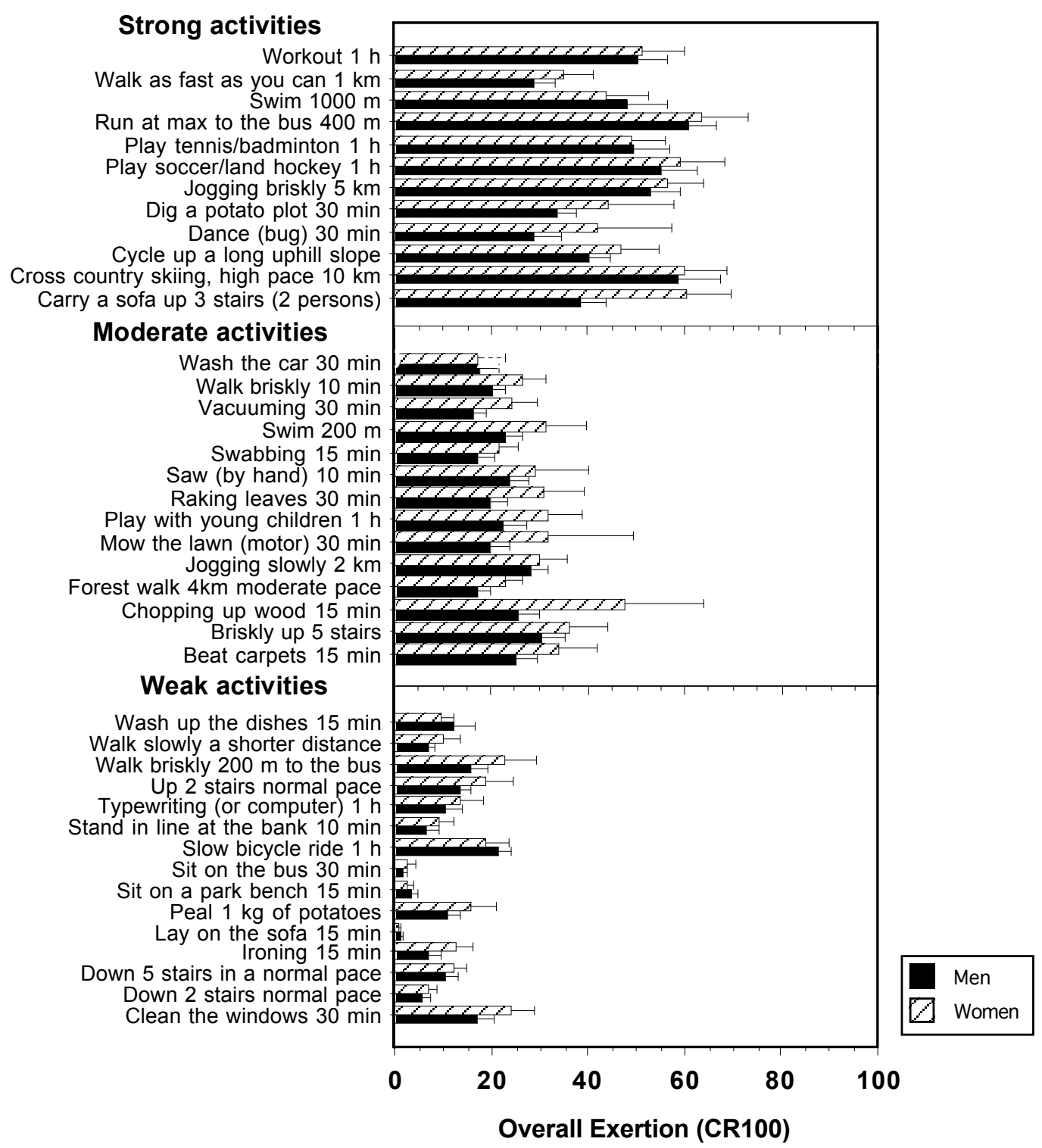

Figure 10. Intensity of "overall exertion" (mean CR100) and 95\% CI for the 41 daily activities and sports activities used in the questionnaire (Figure 2 of Study IV).

\subsection{The multidimensional character of perceived exertion (Study III and Study IV)}

Individual differences in the perceived exertion viewed as a multidimensional construct were determined in Study III (see Figure 11). In Study II a stepwise regression showed that CR10 scale values were correlated to both heart rate and blood lactate. Different discrete symptoms make up the overall perceptual content of perceived exertion and may even contribute differently for different individuals. This multidimensionality may contribute to individual variation in exponents in the psychophysical function. Previously obtained group data were most similar to the results in Figure 11, presented in Diagram a (G. Borg, Ljunggren and Ceci, 1985). In Study III participants were not chosen with regard to exercise habits. It is, however, probable that individual measurement behavior for perceived exertion will vary in a systematic way between different athletic groups, sports, etc., depending on differences in 
bodily demands. This is also in agreement with what was found in Study IV (se above, Section 6.4).

In Study IV, the multidimensional character of perceived exertion was assessed more directly. Participants were asked to measure the perceived intensity of 18 discrete symptoms all involved in overall perceived exertion. Symptom profiles from the questionnaire data showed the most dominant symptoms to be "overall exertion", "breathlessness", "heart pounding", "leg muscle fatigue", "exhaustion" and "sweating". The same symptoms dominated after the bicycle ergometer max test, and except for "exhaustion", also after the sub-maximal test. This might indicate that if scaled alone, some symptoms, like, for example "exhaustion", would give a little higher exponent than, for example, overall perceived exertion or "breathlessness". Hamilton, Killian, Summers, and Jones (1996), indeed obtained different exponents (varying between 1.64 and 2.12) with the CR10 scale for the symptoms "leg effort", "muscle tension", "muscle pain", "muscle discomfort", and "breathing discomfort".

Because of high and significant between-symptom correlations, a factor analysis (principal axis factoring) was run with an oblique rotation. Five factors explained almost $86 \%$ of the initial variance. These five represented:

(1) Muscles and joints ("joint pain", "muscle pain", "joint soreness", "muscle soreness")

(2) Perceived exertion ("breathlessness", "heart pounding", "overall exertion", "sweating", "muscle fatigue", exhaustion)

(3) Annoyance/lack of motivation ("discomfort", "aversion")

(4) Head/stomachh symptoms ("headache", "feeling sick", "ear buzzing")

(5) Cardiopulmonary symptoms ("chest pain", "difficulties breathing").

a)
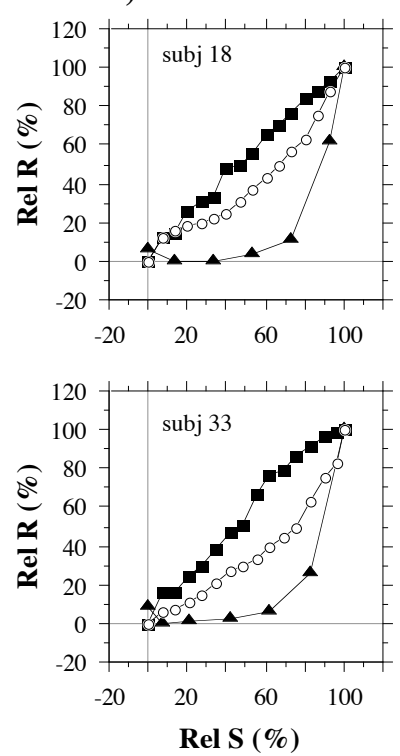

b)
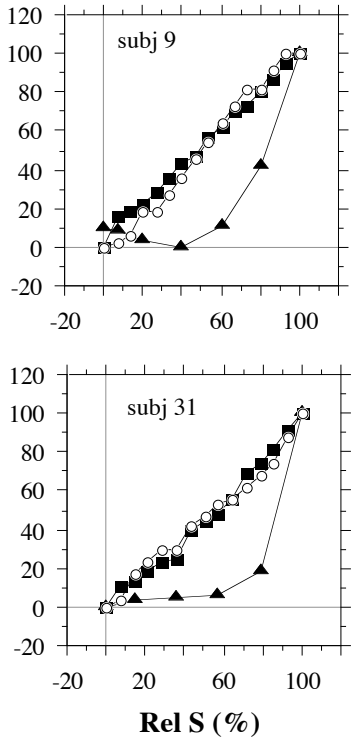

c)
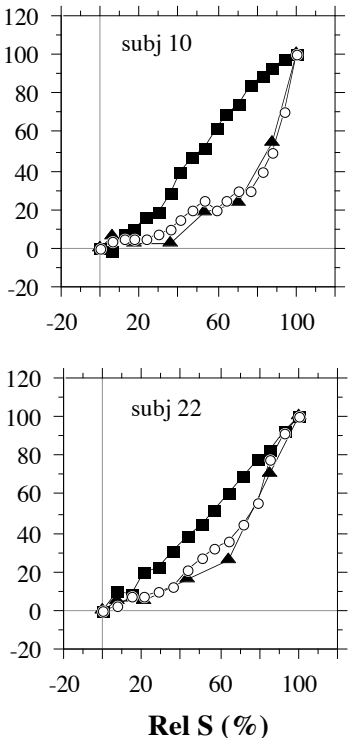

d)
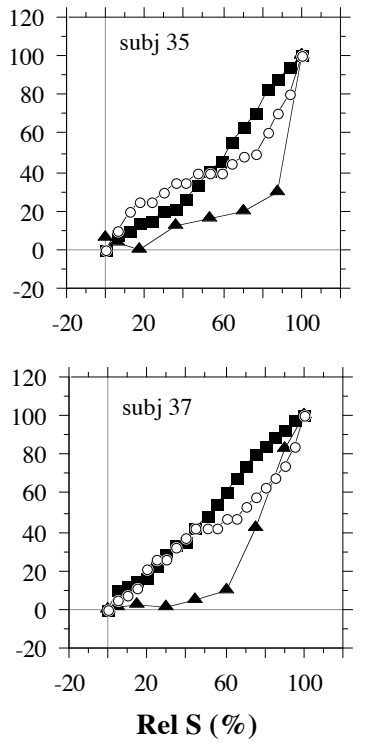

- $\mathrm{HR} \perp[\mathrm{La}-]-\mathrm{O}-\mathrm{CR} 10$

Figure 11. Relative responses, in percent of responses obtained at the maximal workload, of $\mathrm{HR}$, blood lactate, and CR10 scale values of perceived exertion for 8 individuals (Figure 3 in Study III). 
Since the participants agreed well $(85-98 \%$ did not differ in their measurement behavior according to a principal component Q-analysis with participants as "variables"), these results validate the construct of perceived exertion. A secondary factor analyses on the five primary factors (1-5 above), resulted in one general symptom factor (for factors 1, 3, 4 and 5) and one factor for perceived exertion (factor 2).

Four factors (explaining 70\% of the variance) were extracted for the bicycle ergometer max test and two factors (explaining $83 \%$ of the variance) for the sub-maximal test. For the max test, the four factors could be described as:

(1) Physical distress ("joint pain", "bottom soreness", "leg muscle soreness", "leg muscle pain", "headache", "ear buzzing", "chest pain", "difficulties breathing")

(2) Central perceived exertion ("overall exertion", "breathlessness", and "heart pounding")

(3) Annoyance/lack of motivation ("discomfort", "aversion", "feeling sick")

(4) Local perceived exertion ("leg muscle fatigue", "exhaustion" and "sweating").

The interpretation of the four factors obtained for the bicycle ergometer max test, agrees with previous findings based on physiological data (see, e.g., Ekblom \& Goldbarg, 1971; Pandolf, Billings, Drolet, Pimental, and Sawka, 1984) as well as with previous models on self-reported symptomatology during exercise (see, e.g., Pandolf, 1983). However, previous studies mainly focused on physiological variables or used very simple "rating scales".

For the sub-maximal test, only two factors were extracted (Table 12 in Study IV). The factors were:

(1) Annoyance and physical distress ("chest pain", "feeling sick", "joint pain", "difficulties breathing", "headache", "ear buzzing", "discomfort", "aversion", "leg muscle soreness", "leg muscle pain", and "bottom soreness")

(2) Perceived exertion ("heart pounding", "breathlessness", "sweating", "overall exertion", "exhaustion", and "leg muscle fatigue")

That only two factors were obtained in the sub-maximal test was interpreted to be caused by the lower physiological and psychological stress reached at this level (especially in healthy persons). All symptoms in the first factor were given fairly low-intensity values on the CR scale (extremely weak and very weak). The two factors obtained for the sub-maximal level coincided, however, with the global factors of the secondary factor analysis of the questionnaire data and thus further validates the construct of perceived exertion.

Multidimensional scaling resulted in one intensity dimension for both the questionnaire data and the bicycle ergometer data, with the highest values for "overall perceived exertion" and the lowest, for example for "ear buzzing", "headache", "joint pain" and "chest pain". The second dimension for the questionnaire data was interpreted to describe degrees of how somatic or psychological symptoms were. Along this dimension "aversion" was the most psychological and "ear buzzing" the most somatic. For the two bicycle ergometer tests, the second dimension was interpreted to be an activity-specific dimension for bicycling with the highest values for "bottom soreness" and the lowest values for "headache". 

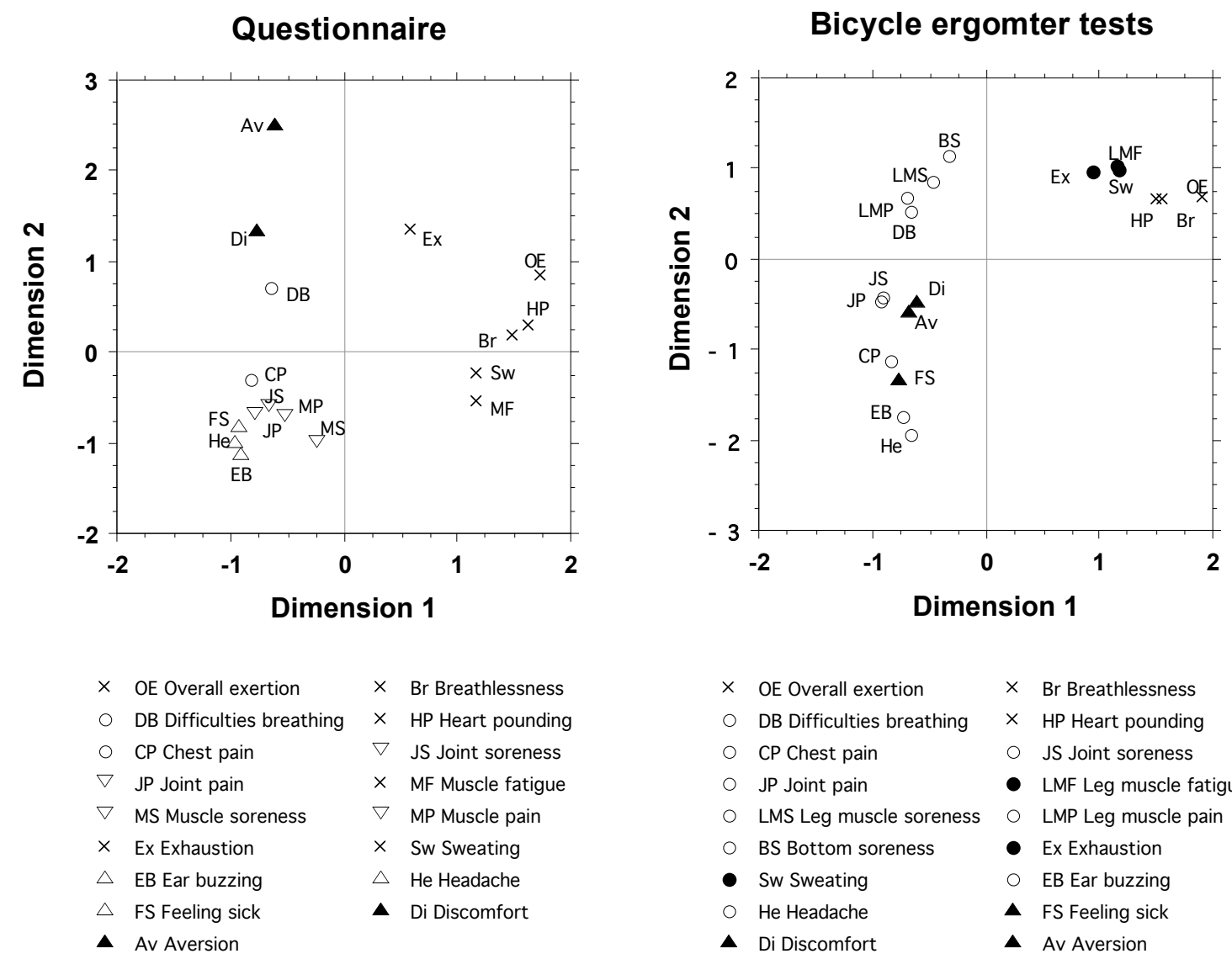
$\times$ OE Overall exertion $\quad \times$ Br Breathlessness
DB Difficulties breathing $\times$ HP Heart pounding
CP Chest pain $\quad$ JS Joint soreness
JP Joint pain $\quad$ LMF Leg muscle fatigue
$\bigcirc$ LMS Leg muscle soreness $\bigcirc \quad$ LMP Leg muscle pain
- BS Bottom soreness - Ex Exhaustion
- Sw Sweating $\bigcirc$ EB Ear buzzing
- He Headache $\Delta$ FS Feeling sick
- Di Discomfort A Av Aversion

Figure 12. Results from the multidimensional scaling of perceived exertion symptoms (Figure 6 and Figure 8 of Study IV). Left panel: Questionnaire data. Right panel: Bicycle ergometer tests data. Below figure: Symptoms classified according to results from the factor analyses.

\subsection{General methodological issues}

This section discusses the important methodological issues: representativeness of cases, generalizability, and issues of reliability and validity.

\subsubsection{Representativness of cases}

All studies reported in this thesis used young to middle age healthy persons, men and women, with little or no prior experience of perceptual scaling. They were fairly homogenous with regard to education (most were university students). Since difference in physical work capacity was used as criteria for validation of the perceptual scales with regard to individual differences and "absolute" levels of intensity, heterogeneity with regard to this variable was sought. This was also fairly well achieved as confirmed by obtained standard deviations in measures of estimated individual work capacity (e.g. $\mathrm{W}_{150}$ and $\mathrm{W}_{170}$ ). These were on average approximately 30-50 Watt.

Since the purpose was neither to describe the population nor to create norms, there was no need for a random sample of the entire population. Rather, as stated in the introduction (Section 4.1), a desire was to use "competent observers" to minimize error due to lack of general understanding of instructions, poor rating behavior, etc. Since previous results 
obtained positive correlations between individual results on aptitude tests and, for example, exponents of psychophysical functions (G. Borg and E. Borg, 1992), using participants with higher education may be one way of ensuring this.

An alternative way may have been by training and instruction. For example, the blackness material used by G. Borg and E. Borg (1991) might have been applied. Further research is, however, needed to study the necessity of this and how much it might improve reliability of reported CR-values. It was therefore not an alternative in this thesis.

\subsubsection{Generalizability of results}

Perceived exertion was tested primarily by bicycle ergometer tests in laboratory environment. Several different test protocols are being used clinically and caution should be taken when generalizing specific results outside the particular test protocols used. Thus, sizes of exponents and estimates of work capacity may be influenced by, for example, kind of protocol and time per workload (cf. the results presented in Study I, II, and III). Since competent observers were used (see above 6.6.1.) average exponents obtained might be somewhat higher than what might, for example, be obtained with a random sample or with a clinical sample.

\subsubsection{Reliability}

Issues of reliability were studied specifically in Study III. Split-half functions and correlations, corrected for attenuation, were computed between coefficients obtained. All correlations were significant ( $\mathrm{p}<0.0001)$. For the RPE scale slope, $r=0.98$ was obtained. For the CR scale exponents, correlations of 0.91 to 0.99 were obtained. For study III:1, estimates of individual work capacity were calculated from individual split half functions and correlations, corrected for attenuation, were above 0.99 .

Parallel test reliability correlations were calculated for the different scales. All correlations were significant $(\mathrm{p}<0.0001)$ and from 0.84 to 0.92 . A reanalysis of data from Study I gave a correlation between CR100 and AME (corrected according to the Range Model) over the four stimulus levels in common to all participants of $r=0.78$. All scales were thus found to be reliable instruments to measure perceived exertion.

\subsubsection{Validity}

Validity can take on several meanings and can be studied in several ways (Cook and Campbell, 1979; Messick, 1995). For measuring instruments like the RPE and CR-scales, validity primarily concerns to what extent the responses given are true to the individuals' feelings and perceptions. This, of course, presupposes a well functioning sensory/perceptual system. It also presupposes the individual's capability of faithfully identifying and reporting feelings and perceptions, with a minimal, or at least rather constant, influence of cognitive processes and personality factors (cf. Figure 1). Even with a continuous increase in sensation and perception matching a continuous increase in stimulation of sensory organs, an individual difference in measurement behavior is unavoidable. Not every individual will be capable of a good identification and of consistently reporting continuous change. So, how then can one go about to assess the validity of the responses obtained with the measuring instruments?

In the area of perceived exertion, there are several physiological variables that just like the verbal reports are responses to sensory stimulation. Such physiological variables can thus be regarded as independent correlates and used to assess concurrent validity of scale responses. Of course, one should not expect, and maybe not even wish, a perfect correlation with some 
single physiological variable. The reason is obviously that the reported perceptions will encompass something more than what can be captured with a few physiological variables. Even if all physiological variables could be measured, one would still not know what weight each should be given. This "weighting" is inherent in our perception.

In the studies of this thesis, heart rate (HR) and blood lactate ([La-]) were used as physiological correlates. Both these variables increase with increasing demands on respiration and working muscles. Several moderate to high correlations of between 0.4 and 0.8 were found at workload levels from 100 to $150 \mathrm{~W}$, between scale responses and the two physiological variables. All three perceptual scales can thus be considered to be valid to measure perceived exertion.

Since the CR10 and CR100 scales use general intensity expressions ("weak" and "strong", etc.), it is reasonable to assume that the scales are equally valid for scaling any sensation, perception or feeling with a continuous variation in intensity. This also agrees with previous results for different perceptual modalities (G. Borg and E. Borg, 1994, 2001). Since the CR100 worked equally well as the CR10 for scaling the different symptoms of perceived exertion, measured after the ergometer test with CR10, and in the questionnaire with CR100, this assumption is validated.

The concept of perceived exertion was introduced close to 50 years ago (G. Borg and Dahlström, 1960; G. Borg, 1962). Since then, the concept and its value have been validated in hundreds of studies and in applications in medicine, ergonomics and sports all over the world (see also G. Borg, 1998). However, very few attempts have been made to investigate the interrelations of more symptoms (Morgan, 1973, Weisser and Stamper, 1977, see also Pandolf, 1983). Study IV of this thesis studied several such symptoms both by a questionnaire and during bicycle ergometer tests. For several symptoms studied in the questionnaire, moderate to high correlations between heart rates and perceived intensity was obtained. This proves the validity of the questionnaire. The similarities of symptoms profiles for exertion on the bicycle ergometer and questionnaire reports can also be regarded as a validation.

\subsection{Criticism of perceptual scaling}

As mentioned in the introduction, S. S. Stevens' concept of ratio scaling, have been met with criticism. Mostly, different systematic errors have been discussed, for example contextual, individual, and methodological effects (see, e.g., Poulton, 1989). Michell (1997) criticized psychology as a whole for not giving enough attention to the question of if what is being measured are quantitative continua. It has also been questioned if the underlying judgments can be any better than ordinal (e.g., Laming, 1997; Svensson, 1998, 2000).

Since the CR-scales are constructed to give reported scale values that grow linearly with magnitude estimation, some of this criticism would also apply to the CR-scale values. This thesis has shown that by anchoring the scale in the conception of a previously experienced maximal perception, the individuals serve as their own controls in a similar way as in magnitude matching (cf. Marks, G. Borg and Ljunggren, 1983). This reduces the individual error variance. By using standard procedures for bicycle ergometer work-tests with one presentation of each stimulus level as well as levels that cover a large part (often the total) of the individual perceptual range, the range-frequency contextual effect is controlled for (cf. Parducci, 1965). Further research is, however, needed on of how different context effects affect CR data (cf. Berglund, 1991). 
In the context of the axiomatic approach to psychological measurement it has also been suggested that at least measurement of perceived intensity is justified and that magnitude estimation is measurement on a ratio scale (Luce, 1997; Narens, 1996). In this thesis perceived intensity of physical exertion was scaled. The argument pursued is that the CRscale values mimic magnitude estimation values; they must also be considered to be on ratio scales (G. Borg and E. Borg, 2001).

In this thesis, heart rate, which grows linearly with physical stimulation for aerobic work (e.g., Åstrand and Rodahl, 1986), was used as a physiological correlate to perceived exertion. Maximal individual performance predicted from heart rate functions agreed well with actual maximal performance (the highest workload an individual achieved on the bicycle ergometer). Perceptual CR-scale values were found to increase positively with increasing stimulation. Individual psychophysical functions for perceived exertion could also be used to predict maximal individual performance. These individual predictions were found to agree well with actual physical performance, and even a little better than the predictions made from the heart rate functions (Table 12, Study III). Such intraindividual agreement shows the value of treating CR-scale values as ratio data. This allows the use of parametric statistics.

Of course, there will always be error and variability. S. S. Stevens was very much aware of this. Already in 1946 he concluded: "Measurement is never better than the empirical operations by which it is carried out, and operations range from bad to good. Any particular scale, sensory or physical, may be objected to on the grounds of bias, low precision, restricted generality, and other factors, but the objector should remember that these are relative and practical matters and that no scale used by mortals is perfectly free of their taint."

\subsection{Final adjustments of the Borg CR100 (centiMax) scale}

Between Study I and IV some adjustments of the CR100 scale were made. The symbolic triangles introduced in the version used in Study I have been removed. Such cues may be added for special purposes (e.g., if participants have difficulties understanding the verbal expressions), but in most situations it is probably more advantageous with a training session beforehand (G. Borg and E. Borg, 1991). Results in Study III also indicated a need of moving "Strong" on the CR100 from 45 to 50 . The main scale range is between the two anchors "Minimal" (2) and "Maximal" (100) with possibilities, in extreme cases, to use numbers above 100. A drawback with allowing answers above "Maximal" is that the scale above "100" becomes more similar to magnitude estimation (with a standard), and that there is a risk of loosing some of the advantages for interindividual comparisons. A way to handle this may be to discuss the answer with the participant and then maybe transform that person's scale values and give the highest answer the number "100". An advantage of keeping the scale open at the upper end is that it better mimics reality and prevents truncation of data.

One great advantage with a CR-scale is that it can be used for two-way communication. That is, not only for estimations but also for production (G. Borg and E. Borg, 2001). Examples are exercise prescription in the form of advice to a patient from a medical doctor or from a coach to an athlete. For this reason, the label "Somewhat strong" was also added to the scale and

placed at 35. Based on results from the studies of this thesis as well as from further ongoing research (not presented here), the latest version of the Borg CR100 (centiMax) scale is presented below (Figure 13). 


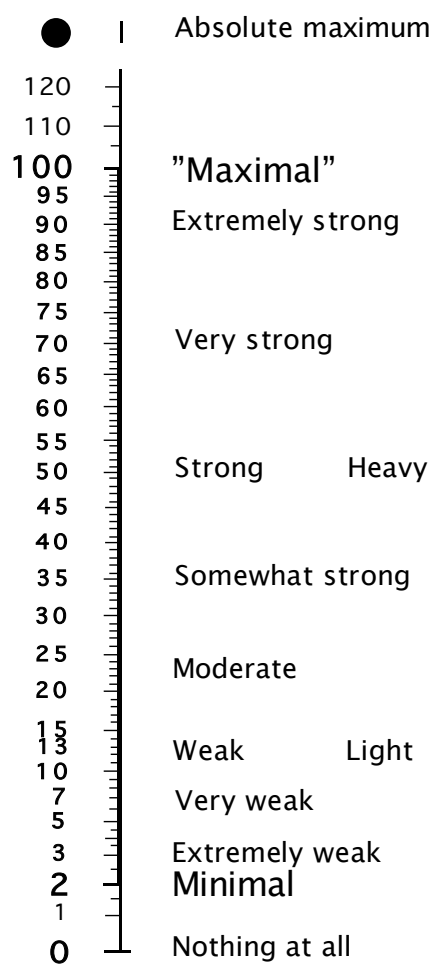

Figure 13. The Borg CR100 (centiMax) scale (C) G. Borg and E. Borg, 1987, 1994, 1998, 2001, 2002, 2004.

\subsection{Areas of application}

The areas where the CR scales, preferably the Borg CR100 (centiMax) scale, may be used are manifold. In this thesis perceived intensity of exertion was at focus. Previous versions of the scale have also been tested on, for example, pain, loudness, taste, odor, and color perception. With promising outcomes, comparisons have been made with results from other types of scales, for example, magnitude estimation, magnitude matching, line production, VAS, and common category scales (e.g., G. Borg and E. Borg, 2001; Griep, E. Borg, Collys, and Massart, 1998; Marks, G. Borg, and Ljunggren, 1983; Marks, G. Borg, and Westerlund, 1992; Neely, 1995). In analogy, it can also be assumed that the Borg CR100 (centiMax) scale will work well for any continuum where the Borg CR10 scale is now used, that is, in clinical diagnostics for perceived exertion, symptom evaluation, pain, "difficulties breathing"; in eating disorders; in rehabilitation of patients with cardiac or musculo-skeletal disorders; in ergonomics and human factors; in sports; in food quality, etc. (see above Section 2.4). Since the CR scales have been found to work well for perceptions of sensory intensities, and better than common category "rating scales", there is good reason for an extended use in other intensity evaluations. Research has for example recently been started where the more finegraded CR100 is used to study emotions among professional and amateur choral singers. Another ongoing study concerns athletic elite-performances in diving and ski jumping. 


\section{Acknowledgment}

To write a good thesis in psychology is a craft that requires "fingertip feelings", takes lots of patience, and some good luck. You stretch out your hand, learn of intriguing methods and try to grasp something beautiful and fascinating. Like a butterfly, psychology has a somewhat ethereal beauty, and to succeed with psychological research may be like getting a butterfly to land on your index finger. It makes you very happy, but can only be done with patience and some good luck. Good methodology will, however, make it easier, as will certainly good tutorship and the encouragement and support from friends and family.

First of all, I want to express my sincere gratitude to my supervisor, Professor Birgitta Berglund. Her broad expertise, enthusiasm, and energy have been a source of great inspiration. Moreover, her guidance and support have helped me become a more confident researcher and to trust my own knowledge and capacities.

I want to express my gratitude my co-authors Professor Gunnar Borg and Professor Lennart Kaijser for interesting discussions, and for generously providing research resources that have made this thesis possible. I am also thankful to all colleagues of the International Society for Psychophysics, who have greatly encouraged me at every Fechner Day conference I was able to attend. Thank you for posing good questions and giving constructive comments on posters and oral presentations! Thank you also for making me feel as one in "the scientific team"!

I also wish to thank all friends, former and present colleagues at the Department of Psychology, for encouragement, support, chats, and laughter. Peter Hassmén and Greg Neely for encouraging me to enter into the $\mathrm{PhD}$ program. Henry Montgomery for his generous complements on my writing. Jan Dahlkvist, Hannes and Anna Eisler, Anita Gidlöf-Johansson, Eva-Liz Harju, Nathalie Hassmén, Åke Hellström, Ingegerd Johansson, Farah Moniri, Mats E. Nilsson, Gunilla Preissler, Maria Sandgren, Margaretha Simonsson-Sarnecki, Joakim Westerlund, Li Zheng and many more colleagues and fellow graduate students for being supportive and good friends. I would also like to express my gratitude to all administrative staff at the department, especially Britth Sandin, Eva Sjökvist, Eva Persdotter and Barbro Svensson, and the technical staff Peter Almlöf, Håkan Bergqvist, Henrik Dunér and KarlArne Tingström. You all made my life smoother.

My gratitude also includes the Swedish Council for Research in the Humanities and Social Sciences (HSFR, now a part of the Swedish Research Council), the Swedish National Centre for Research in Sports, and the Department of Psychology, for financial support of my research.

Finally, I want to thank all my non-academic friends who have had to endure my moaning and wining or, maybe worse, my, in their view, mysterious explanations and unintelligible enthusiasm. Last, but certainly not least, I want to thank my brother Per, his wife Katarina and my lovely nephew Fredrik, and of course my parents, Gunnar and Vivi-Anne Borg, for their unerring support. As a child of five or six, my brother-arguing like boys do about whose Dad was the strongest and had the most important work-brushed off his friends by saying: "My Dad doesn't work, he thinks!" Thanks, Dad, for showing me that one can work by thinking! 


\section{References}

Allen, D., and Westerblad, H. (2004). Physiology. Lactic acid -the latest performance-enhancing drug, Science, $305,1112-1113$.

Algom, D., and Marks, L. E. (1990). Range and regression, loudness scales, and loudness processing: toward a context-bound psychophysics, Journal of Experimental Psychology and Human Perceptual Performance, 16, 706-27.

Åstrand, P.-O., and Rodahl, K. (1986). Textbook of work physiology (3 ${ }^{\text {rd }}$ edition). New York: McGraw-Hill.

Baird, J. C., and Noma, E. (1975). Psychophysical Study of Numbers. I. Generation of Numerical Responses. Psychological Research, 37, 281-297.

Bartoshuk, L. (2000). Comparing sensory experiences across individuals: Recent psychophysical advances illuminate genetic variation in taste perception. Chemical Senses, 25, 447-460.

Berg, C., Brodin, U., Lindberg, G., and Södersten, P. (2002). Randomized controlled trial of a treatment for anorexia and bulimia nervosa. Proceedings of the National Academy of Sciences, 99, 9486-9491.

Berglund, M. B. (1991). Quality assurance in environmental psychophysics. In S.J. Bolanowski and G.A. Gescheider (Eds.), Ratio scaling of psychological magnitude: In Honor of the Memory of S. S. Stevens (pp. 140-162). Hillsdale, NJ: Erlbaum.

Berglund, B., Berglund, U., and Lindberg, S. (1983). Master scaling of environmental loudness. Reports from the Department of Psychology, Stockholm university, No. 610.

Berglund, B., Berglund, U., and Lindvall, T. (1974). A psychological detection method in environmental research. Environmental Research, 7, 342-352.

Berglund, B., Berglund, U., and Lindvall, T. (1978). Separate and joint scaling of perceived odor intensity of nbutanol and hydrogen sulfide. Perception and Psychophysics, 23, 313-320.

Berglund, B., and Harju, E. L. (2003). Master scaling of perceived intensity of touch, cold and warmth. European Journal of Pain, 7, 323-334.

Berglund, B., Harju, E. L., Kosek, E., and Lindblom, U. (2002). Quantitative and qualitative perceptual analysis of cold dysesthesia and hyperalgesia in fibromualgia. Pain, 96, 177-187.

Berglund, B., and Nordin, S. (1990). Utilizing individual differences in loudness measurement. In F. Müller (Ed). Fechner Day 90. Proceedings of the Sixth Annual Meeting of the International Society for Psychophysics (pp. 117-122). Würzburg, Germany: International Society for Psychophysics.

Berglund, B., and Nordin, S. (1992). Detectability and perceived intensity for formaldehyde in smokers and nonsmokers. Chemical Senses, 17, 291-306.

Borg, E., and Borg, G. (2002). A Comparison of AME and CR100 for Scaling Perceived Exertion. Acta Psychologica, 109, 157-175.

Borg, E., and Kaijser, L (2006). A comparison between three rating scales for perceived exertion and two different work tests. Scand J Med Sci Sports, 16: 57-69.

Borg, G. (1961). Interindividual scaling and perception of muscular force. Kungliga fysiografiska sällskapets $i$ Lund förhandlingar, 12 (31), 117-125.

Borg, G. (1962). Physical performance and perceived exertion. Studia Psychologica et Paedagogica, Series altera, Investigationes XI. Lund, Sweden: Gleerup.

Borg, G. (1970). Perceived exertion as an indicator of somatic stress. Scandinavian Journal of Rehabilitation Medicine, 2, No. 2-3, 92-98.

Borg, G. (1972). A ratio scaling method for interindividual comparisons. Report from the Institute of Applied Psychology, the University of Stockholm, No. 27.

Borg, G. (1973a). Perceived exertion during walking: A psychophysical function with two additional constants. Reports from the Institute of Applied Psychology, Stockholm university, No. 39.

Borg, G. (1973b). A note on a category scale with "ratio properties" for estimating perceived exertion. Reports from the Institute of Applied Psychology, Stockholm University, No. 36.

Borg, G. (1977). (Ed.) Physical work and effort. Wenner-Gren Center International Symposium Series, Vol. 28. Oxford: Pergamon Press, $434 \mathrm{pp}$.

Borg, G. A. V. (1982). A category scale with ratio properties for intermodal and interindividual comparisons.In H.-G. Geissler and P. Petzold (Eds.), Psychophysical Judgement and the Process of Perception (pp. 25-34). Berlin: VEB Deutscher Verlag der Wissenschaften.

Borg, G. (1990). A General Model for Interindividual Comparison. In Jm. W. Baker, M.E. Hyland, R. van Hezewijk, and S. Terwee (Eds.), Recent Trends in Theoretical Psychology, Volume II, (pp. 439-444). New York: Springer-Verlag.

Borg, G. (1991). General and differential characteristics of lactate functions. In N. Bachl, T. E. Graham, and H. Löllgen (Eds.), Advances in Ergometry (pp. 149-152). Berling: Springer. 
Borg, G. (1992). A "fixed star" for interprocess comparisons. In G. Borg, and G. Neely (Eds.), Fechner Day 92. Proceedings of the Eight Annual Meeting of the International Society for Psychophysics (pp. 41-45). Stockholm: Department of Psychology, Stockholm Univeristy.

Borg, G. (1998). Borg's Perceived Exertion and Pain Scales. Champaign, IL:Human Kinetics.

Borg, G., and Borg, E. (1987). The need of an additional constant in the psychophysical function of taste perception. Reports from the Department of Psychology, Stockholm university, No. 668.

Borg, G., and Borg, E. (1991). A general psychophysical scale of blackness and its possibilities as a test of rating behaviour. Reports from the Department of Psychology, Stockholm university, No. 737.

Borg, G., and Borg, E. (1992). Intelligence and rating behavior in a psychophysical study of size. Reports from the Department of Psychology, Stockholm University. No. 758.

Borg, G., and Borg, E. (1994). Principles and experiments in Category-Ratio scaling. Reports from the Department of Psychology, Stockholm university, No.789.

Borg, G., and Borg, E. (2001). A new generation of scaling methods: Level-anchored ratio scaling. Psychologica, 28, 15-45.

Borg, G., Diamant, H., Ström, L., and Zotterman, Y. (1967). Neural and perceptual intensity. Journal of Physiology, 191, 118-119.

Borg, G., Hassmén, P., and Lagerström, M. (1987). Perceived exertion related to heart rate and blood lactate during arm and leg exercise. European Journal of Applied Physiology, 65, 679-685.

Borg, G., and Hosman, J. (1970). The metric properties of adverbs. Reports from the Institute of Applied Psychology, Stockholm University, No. 7.

Borg, G., and Lindblad, I. (1976). The determination of subjective intensities in verbal descriptions of symptoms. Reports from the Institute of Applied Psychology, Stockholm University, No. 75.

Borg, G., Ljunggren, G., and Marks, L. E. (1985). General and differential aspects of perceived exertion and loudness assessed by two new methods. Reports from the Department of Psychology, Stockholm University, No. 636.

Borg, G., Ljunggren, G. and Ceci, R. (1985). The increase of perceived exertion, aches and pain in the legs, heart rate and blood lactate during exercise on a bicycle ergometer. European Journal of Applied Physiology, 54, $343-349$.

Borg, G. A. V., and Marks, L. E. (1983). Twelve meanings of the measure constant in psychophysical power functions. The Bulletin of the Psychonomic Society, 21, 73-75.

Borg, G., Skinner, J. S., and Bar-Or, O. (1972). Self-appraisal of physical performance capacity. Report from the Institute of Applied Psychology, the University of Stockholm, No. 32.

Buckley, J. P., Eston, R. G., and Sim, J. (2000). Ratings of perceived exertion in braillle: validity and reliability in production mode. British Journal of Sports Medicine, 34, 297-302.

Cliff, N. (1959). Adverbs as multipliers. Psychological Review, 66, 27-44.

Cook, T. D., and Campbell, D. T. (1979). Quasi-Experimentation. Design and Analysis Issues for Field Settings. Boston: Houghton Miffin Company.

Coren, S., Ward, L. M., and Enns, J. T. (1994). Sensation and Perception. (4 ${ }^{\text {th }}$ ed). Orlando, FL: Hartcourt Brace and Co.

Corso, J. F. (1963). A theoretico-historical review of the threshold concept. Psychological Bulletin, 60, 356-370.

Dedering, A., Németh, G., and Harms-Ringdahl, K. (1999). Correlation between electromyographic spectral changes and subjective assessment of lumbar "muscle fatigue" in subjects without pain from the lower back. Clinical Biomechanics, 14, 103-111.

Drury, C. G., Atiles, M., Chaitanya, M., Lin, J. F., Marin, C., Nasarwanji, M., Paluszak, D., Russel, C., Stone, R., and Sunm, M. (2006). Vicarious perception o postural "discomfort" and exertion. Ergonomic, 49, 14701485.

Dubach, P., Sixt, S., and Myers, J. (2001). Exercise training in chronic heart failure: why, when and how. Swiss Medical Weakly, 131, 510-514.

ECA. (1999). Sensory evaluation of indoor air quality. ECA indoor air quality \& its impact on man, Report 20. Luxemburg: Office for Official Publications of the Europe Communities.

Eisler, H. (1962). Empirical test of a model relating magnitude and category scales. Scandinavian Journal of Psychology, 3, 88-96.

Eisler, H. (1965). The ceiling of psychophysical power functions. The American journal of psychology, 78, 506509.

Eisler, H., and Montgomery, H. (1974). On theoretical an realizable ideal conditions in psychophysics: Magnitude and category scales and their relation. Perception and Psychophysics, 16, 157-168.

Ekblom, B., and Goldbarg, A. N. (1971). The influence of physical training and other factors on the subjective rating of perceived exertion. Acta Physiologica Scandinavica, 83, 399-406.

Ekman, G. (1959). Weber's law and related functions. Journal of Psychology, 47, 343-352.

Ellermeier, W., Westphal, W., and Heidenfelder, M. (1991). On the "absoluteness" of category and magnitude 
scales of pain. Perception and Psychophysics, 49, 159-166.

Eston, R. G., Lamb, K. L., Parfitt, G., and King, N. (2005). The validity of predicting maximal oxygen uptake from a perceptually-regulated graded exercise test. European Journal of Applied Physiology, 94, 221-227.

Fanger, P. O. (1988). Introduction of the olf and decipol units to quantify air pollution perceived by humans indoors and outdoors. Energy and Buildings, 12, 1-6.

Garriga-Trillo, A., Muro, P., and Merino, J. M. (2002). An application of Borg's CR10 scale to wine tasting. In J. A. Da Silva, E. H. Matsushima, and N. P. Ribeiro-Filho (Eds.). Fechner Day 2002. Proceedings of the eighteenth annual meeting of the International Society for Psychophysics (pp 278-283). Brazil, Rio de Janeiro: The International Society for Psychophysics.

Geddes, E. L., Reid, W.D., Crowe, J., O’Brien, K., and Brooks, D. (2005). Inspiraroty muscle training in adults with chronic obstructive pulmonary disease: a systematic review. Respiratory Medicine, 99, 1440-1458.

Gescheider, G. A. (1997). Psychophysics. The Fundamentals (3rd ed.). Mahwah, NJ: Lawrence Erlbaum.

Green, B. G., Shaffer, G. S., and Gilmore, M. M. (1993). Derivation and evaluation of a semantic scale of oral sensation magnitude with apparent ratio properties. Chemical Senses, 18, 683.702.

Green, B. G., Dalton, P., Cowart, B., Shaffer, G., Rankin, K., and Higgins, J. (1996). Evaluating the 'Labeled Magnitude Scale' for measuring sensations of taste and smell. Chemical Senses, 21, 323-334.

Griep, M.I., Borg, E., Collys, K., and Massart, D. L. (1998). Category ratio scales as an alternative to magnitude matching for age-related taste and odour perception. Food Quality and Preference, 9, 67-72.

Guilford, J. P. (1936, 1954). Psychometric methods. New York: McGraw.

Harju, E. -L. (2002). Cold and warmth perception mapped for age, gender, and body area. Somatosensory \& Motor Research, 19, 61-75.

Harms-Ringdahl, K. (1986). On assessment of shoulder exercise and load-elicited pain in the cervical spine. Biomechanical analysis of load - EMG - methodological studies of pain provoked by extreme position. Scandinavian Journal of Rehabilitation Medicine, Suppl., 14, 1-40.

Harms-Ringdahl, K., Brodin, H., Eklund, L., and Borg, G. (1983). "discomfort" and pain from loaded passive joint structures. Scandinavian Journal of Rehabilitation Medicine, 15, 205-211.

Hand, D. J. (1996). Statistics and the theory of measurement. Journal of the Royal Statistical Society, 159, 3, 445 -492 .

Hellman, R., and Zwislocki, J. J. (1963). Monaural loudness function at $1000 \mathrm{cps}$ and interaural summation. Journal of the Acoustical Society of America, 35, 856-865.

Hosman, J., and Borg, G. (1970). The mean and standard deviation of cross-modality matches: A study of individual scaling behavior. Reports from the Institute of Applied Psychology, Stockholm University, No. 3.

Hummel, A., Läubli, T., Pozzo, M., Schenk, P., Spillmann, S., and Klipstein, A. (2005). Relationship between perceived exertion and mean power frequency of the EMG signal from the upper trapezius muscle during isometric shoulder elevation. European Journal of Applied Physiology, 95, 321-326.

Johnson, K. O., Hsiao, s. s., and Yoshioka, T. (2002). Neural Coding and the Basic Law of Psychophysics. The neuroscientist, 8, 111-121.

Jones, F. N., and Markus, M. J. (1961). The subject effect in judgments of subjective magnitude. Journal of Experimental Psychology, 61, 40-44.

Knibestöl, M., and Vallbo, Å. B. (1980). Intensity of sensation related to activity of slowly adapting mechanoreceptive units in the human hand. Journal of Physiology, 300, 251-267.

Laming, D. (1997). The measurement of sensation. Oxford: Oxford University Press.

Lockhead, G. R. (1992). Psychophysical scaling: Judgments of attributes or objects? Behavioral and Brain Sciences (with peer commentaries), 15, 543-601.

Lockhead, G. R. (2004). Absolute judgments are relative: A reinterpretation of some psychophysical ideas. Review of General Psychology, 8, 265-272.

Lord, F. M. and Novick, M. R. (1968). Statistical theories of mental test scores. Reading, MA: Addison-Wesley Publishing Company.

Luce, R. D. (1990). "On the Possible Psychophysical Laws" Revisited: Remarks on Cross-Modal Matching. Psychological Review, 97, 66-77.

Luce, R. D. (1997). Quantification and symmetry: Commentary on Michell, Quantitative science and the definition of measurement in psychology. British Journal of Psychology, 88, 395-398.

Luce, R. D., and Green, D. M. (1974). The response ratio hypothesis for magnitude estimation. Journal of Mathematical Psychology, 11, 1-14.

Luce, R. D., and Krumhansl, C. (1988). Measurement, scaling, and psychophysics. In R. C. Atkinson, R. J. Herrnstein, G. Lindzey, and R. D. Luce (Eds.) Stevens' Handbook of Experimental Psychology (pp. 1-74). New York: Wiley.

Mahler, D. A., and Horowitz, M. B. (1994). Clinical evaluation of exertional dyspnea. Clinical Chest Medicine, $15,259-269$. 
Mahler, D. A., Mejia-Alfaro, R., Ward, J., and Baird, J. C. (2001). Continuous measurement of "breathlessness" during exercise: validity, reliability, and responsiveness. Journal of Applied Physiology, 90, 2188-2196.

Marks, L. M. (1974). Sensory processes. The new psychophysics. New York: Academic Press.

Marks, L. E. (1988). Magnitude estimation and sensory matching. Perception and Psychophysics, 43, 511-525.

Marks, L. E., Borg, G., and Ljunggren, G. (1983). Individual differences in perceived exertion assessed by two new methods. Perception and Psychophysics, 34, 280-288.

Marks, L. E., Borg, G., and Westerlund, J. (1992). Differences in taste perception assessed by magnitude matching and by category-ratio scaling. Chemical Senses, 17, 493-506.

Marks, L. E., and Gescheider, G. A. (2002). Psychophysical scaling In H. Pashler, and J. Wixted (Eds). Stevens' handbook of experimental psychology (3rd ed.), Vol. 4: Methodology in experimental psychology. (pp. 91138). Hoboken, NJ, US: John Wiley and Sons, Inc.

Marks, L. E., and Stevens, J. C. (1968). The form of the psychphys func near threashold. Perception \& Psychophysics, 4, 315-318.

Messick, S. (1995). Validity of Psychological Assessment. American Psychologist, 50, 741-749.

Michell, J. (1997). Quantitative science and the definition of measurement in psychology. British Journal of Psychology, 88, 355-383.

Miles, M.P., and Clarkson P. M. (1994). Exercise-induced "muscle pain", soreness, and cramps. Journal of Sports Medicine and Physical Fitness, 34, 203-16.

Möller, S. (2000). Assessment and prediction of speech quality in telecommunication. Boston: Kluwer Academic Publishers.

Morgan, W. P. (1973). Psychological factors influencing perceived exertion. Medicine and science in sports, 5, 97-103.

Morgan, W. P. (1994). Psychological components of effort sense. Medicine and Science in Sports and Exercise, 26, 1071-1077.

Mountcastle, V. B., Poggio, G. F., and Werner, G. (1963). The relation of thalmaic cell response to peripheral stimuli varied over an intensive continuum. Journal of Neurophysiology 26, 807-834.

Myers, J. N. (1994). Perception of "chest pain" during exercise testing in patients with coronary artery disease. Medicine and Science in Sports and Exercise, 26, 1082-1086.

Narens, L. (1996). A Theory of Ratio Magnitude Estimation. Journal of Mathematical Psychology, 40, 109-129.

Neely, G. (1995). Category-ratio scaling of sensory magnitude in comparison with other methods. Thesis. Stockholm: Stockholm university.

Neely, G., and Borg, E. (1995). Properties of a Category Ratio scale (CR10) and the Visual Analogue scale (VAS): A comparison with Magnitude Estimation, Line Production, and Category Scaling. Reports from the Department of Psychology, Stockholm university, No.791. [Also In G.W. Neely (Ed) (1995), Categoryratio scaling of sensory magnitude in comparison with other methods, Doctoral Dissertation.]

Neely, G., Ljunggren, G., Sylvén, C., and Borg, G. (1992). Comparison between the visual analogue scale (VAS) and the category ratio scale (CR-10) for the evaluation of leg exertion. Inernational Journal of Sports Medicine, 13, 133-136.

Nieder, A., and Miller, E. K. (2003). Coding of Cognitive Magnitude: Compressed Scaling of Numerical Information in the Primate Prefrontal Cortex. Neuron, 37, 149-157.

Pandolf, K. B. (1978). Influence of local and central factors in dominating rating perceived exertion during physical work. Perceptual and Motor Skills, 46, 683-698.

Pandolf, K. B. (1983). Advances in the study and application of perceived exertion. Exercise and Sport Sciences Reviews, 11, 118-158.

Pandolf, K. B., Billings, D. S., Drolet, L. L., Pimental, N. A., and Sawka, M. N. (1984). Differential ratings of perceived exertion and various physiological responses during prolonged upper and lower body exercise. European Journal of Applied Physiology, 53, 5-11.

Parducci, A. (1965). Category Judgment: A range-frequency model. Psychological Review, 72, 407-418.

Pashler and Yantis (Eds), 2002; Stevens' handbook of experimental psychology. Vol 1. Sensation and perception (3rd ed.). New York: Wiley.

Passer, M. W., and Smith, R. E. (2004). Psychology: the science of mind and behaviour (2nd ed.). New York: McGraw-Hill.

Pedersen, B. K., and Saltin, B. (2006). Evidence for prescribing exercise as therapy in chronic disease. Scandinavian Journal of Medicine in Science and Sports, 16 (Suppl 1), 3-63.

Poulton, E. C. (1968). The new psychophysics: six models for magnitude estimation. Psychological Bulletin, 69, 1-19.

Poulton, E. C. (1989). Bias in quantifying judgements. Hillsdale, NJ: Erlbaum.

Price,D. D., McGrath, P. A., Rafi, A., and Buckingham, B. (1983). The validation of visual analogue scales as ratio scale measures for chronic and experimental pain. Pain, 17, 45-56.

Richardson, L. F., and Ross, J. S. (1930). Loudness and telephone current. Journal of General Psychology, 3, 
288-304.

Ries, A. L. (2005). Minimally clinically important differences for the UCSD shortness of breath questionnaire, Borg scale, and Visual Analog Scale. COPD, 2, 105-110.

Russel, W. D. (1997). On the current status of perceived exertion. Perceptual and Motor Skills, 84, 799-808.

Sagal, P., and Borg, G. (1993). The range principle and the problem of other minds. British Journal for the Philosophy of Science, 44, 477-491.

Schneider, B., and Parker, S. (1990). Does stimulus context affect loudness or only loudness judgements? Perception \& Psychophysics, 48, 409-418.

Sjögren, T., Nissinen, K. J. N., Järvenpää, S. K., Ojanen, M. T., Vanharanta, H., and Mälkiä, E. A. M. (2005). Effects of a workplace physical exercise intervention on the intensity of "headache" and neck and shoulder symptoms and upper extremity muscular strength of office workers: A cluster randomized controlled crossovertrial. Pain, 116, 119-128.

Sjöstrand, T. (1947). Changes in the respiratory organs of workmen at an ore melting works. Acta Medica Scandinavia, (Suppl. 196): 687.

Stendardi, L., Grazzini, M., Gigliotti, F., Lotti, P., and Scano, G. (2005). Dyspnea and leg effort during exercise. Respiratory Medicine, 99, 933-942.

Sternberg, R. J. (2006). Cognitive Psychology. Belmont, CA, Thomson Wadsworth.

Stevens, J. C. (1976). Equal-sensation functions generated by the method of magnitude estimation. Journal of the Acoustic Society of America, 59, 473-474.

Stevens, J. C., and Marks, L. E. (1980). Cross-Modality matching functions generated by magnitude estimation. Perception \& Psychophysics, 27, 379-389.

Stevens, S. S. (1946). On the theory of scales of measurement. Science, 103, 677-680.

Stevens, S. S. (1957). On the psychophysical law. Psychological Review, 78, 426-450.

Stevens, S. S. (1971). Issues in psychophysiological measurement. Psychological Review, 78, 426-450.

Stevens, S. S. (1975). Psychophysics: Introduction to its perceptual, neural and social prospects. New York, Wiley.

Stevens, S. S., and Galanter, E. H. (1957). Ratio scales and category scales for a dozen perceptual continua. Journal of Experimental Psychology, 54, 377-411.

Svensson, E. (1998). Ordinal invariant measures for individual and group changes in ordered categorical data. Statistics in Medicine, 17, 2923-2936.

Svensson, E. (2000). Concordance between ratings using different scales for the same variable. Statistics in Medicine, 19, 3483-3496.

Teghtsoonian, R. (1971). On the exponents in Stevens' law and the constant in Ekmans law. Psychological Review, 78, 71-80.

Teghtsoonian, R. and Teghtsoonian, M. (1997). Range of acceptable stimulus intensities: An estimator of dynamic range for intensive perceptual continua. Perception \& Psychophysics, 59, 721-728.

Wahlund, H. (1948). Determination of the physical work capacity. Acta Medica Scandinavia (Suppl. 215).

Vieira, E. R., Kumar, S., Coury, H. J. C. G., and Narayan, Y. (2005). Low back problems and possible improvements in nursing jobs. Journal of Advanced Nursing, 55, 79-89.

Ward, L. M. (1992). Who knows? In G. Borg and G. Neely (Eds.), Fechner Day 92. Proceedings of the Eighth Annual Meeting of the International Society for Psychophysics (pp. 217-222). Stockholm: The International Society for Psychophysics.

Ward, L. M. (1997). On establishing a convention for psychophysical measurement. In A. Preis, and T. Hornowski (Eds.), Fechner Day 97. Proceedings of the $13^{\text {th }}$ Annual Meeting of the International Society for Psychophysics (pp. 315-319). Poznan, Poland: The International Society for Psychophysics.

Ward, L. M. (2006). S.S. Stevens' legacy: An ideal psychophysical law? In Kornbrot, D. E., Msetfi, R. M., and MacRae, A. W. (Eds.). Fechner Day 2006. Proceedings of the $22^{\text {nd }}$ Annual Meeting of the International Society for Psychophysics (pp. 43-48). St Albans, UK: The International Society for Psychophysics.

Weisser, P. C., and Stamper, D. A. (1977). Psychophysiological interactions leading to increased effort, leg fatigue, and respiratory distress during prolonged strenuous bicycle riding. In G. Borg (Ed.), Physical work and effort (pp. 401-416). Oxford: Pergamon Press.

Weisser, P. C., Kinsman, R. A., and Stamper, D. A. (1973). Task-specific symptomatology changes resulting from prolonged submaximal bicycle riding. Medicine and Science in Sports, 5, 79-85.

West, R.L., Ward, L. M., and Kohsla, R. (2000). Constrained scaling: The effect of learned psychophysical scales on idiosyncratic response bias. Perception \& Psychophysics, 62, 137-151.

Williams, A.C. de C., Davies, H. T. O, and Chadury, Y. (2000). Simple pain rating scales hide complex idiosyncratic meanings. Pain, 85, 457-463.

Zwislocki, J. J., and Goodman, D. A. (1980). Absolute scaling of sensory magnitude: A validation. Perception \& Psychophysics, 28, 28-38. 


\section{Appendix}

Table 1. Chi-square significance, Pseudo $\mathrm{R}^{2}$ (Cox and Snell R Square - Nagelkerke R Square), and percentage correct predictions of the logistic regression performed for data from 32 subjects ( 16 men and 16 women) of Study I $(120 \mathrm{~W})$, from 40 subjects (24 men and 16 women) of Study III:1 (120 W of the max-test and $120 \mathrm{~W}$ of the submaximal test), and from 24 subjects (12 men and 12 women) of Study III:2 (125 W).

\begin{tabular}{lllllll}
\hline & & & & \% correct \\
Study, test & Variable & $\chi_{1}^{2}$ & Pseudo $^{2}$ & Men & Women & Overall \\
\hline St I & HR(AME) & $16.5(\mathrm{p}<0.001)$ & $0.40-0.54$ & 75.0 & 75.0 & 75.0 \\
120 W & AME & $0.92(\mathrm{p}=0.336)$ & $0.03-0.04$ & 81.3 & 31.3 & 56.3 \\
& AME & $11.9(\mathrm{p}<0.001)$ & $0.31-0.41$ & 68.8 & 81.3 & 75.0 \\
& HR(CR100) & $10.7(\mathrm{p}=0.001)$ & $0.28-0.38$ & 75.0 & 75.0 & 75.0 \\
& CR100 & $12.7(\mathrm{p}<0.001)$ & $0.33-0.44$ & 81.3 & 68.8 & 75.0 \\
St III:1, & HR & $28.8(\mathrm{p}<0.001)$ & $0.51-0.69$ & 95.8 & 81.3 & 90.0 \\
Max 120 W & RPE & $22.3(\mathrm{p}<0.001)$ & $0.43-0.58$ & 91.7 & 75.0 & 85.0 \\
& CR10 & $17.4(\mathrm{p}<0.001)$ & $0.35-0.48$ & 91.7 & 62.5 & 80.0 \\
St III:1, & HR & $29.1(\mathrm{p}<0.001)$ & $0.52-0.70$ & 91.7 & 68.8 & 82.5 \\
Sub-max 120 W W & CR10 & $18.2(\mathrm{p}<0.001)$ & $0.37-0.50$ & 95.8 & 62.5 & 82.5 \\
St III:2, 125 W & HR(RPE) & $9.16(\mathrm{p}=0.002)$ & $0.32-0.42$ & 66.7 & 83.3 & 75.0 \\
& RPE & $9.87(\mathrm{p}=0.002)$ & $0.34-0.45$ & 75.0 & 83.3 & 79.2 \\
& CR100 & $7.95(\mathrm{p}=0.005)$ & $0.28-0.39$ & 66.7 & 75.0 & 70.8 \\
& HR(CR10) & $10.8(\mathrm{p}=0.001)$ & $0.36-0.49$ & 58.3 & 83.3 & 70.8 \\
& CR10 & $8.50(\mathrm{p}=0.004)$ & $0.30-0.40$ & 83.3 & 66.7 & 75.0 \\
\hline
\end{tabular}


Table 2. Logistic regression Equations of models also presented in Table 1.

\begin{tabular}{|c|c|c|c|c|c|c|}
\hline Study, test & Variable & & B & $\mathrm{SE}$ & Wald $(\mathrm{df}=1)$ & $\operatorname{Exp}(B)$ \\
\hline St I & HR(AME) & $\mathrm{B}_{1}$ & 0.114 & 0.040 & $8.18(p=0.004)$ & 1.21 \\
\hline \multirow{9}{*}{$120 \mathrm{~W}$} & & $\mathrm{~B}_{0}$ & -15.6 & 5.46 & $8.15(p=0.004)$ & \\
\hline & AME & $\mathrm{B}_{1}$ & 0.014 & 0.016 & $0.85(\mathrm{p}=0.355)$ & 1.01 \\
\hline & & $\mathrm{B}_{0}$ & -0.30 & 0.47 & $0.40(p=0.530)$ & \\
\hline & $\mathrm{AME}_{\mathrm{Rt}}$ & $\mathrm{B}_{1}$ & 0.066 & 0.025 & $7.15(p=0.008)$ & 1.07 \\
\hline & & $\mathrm{B}_{0}$ & -4.76 & 1.88 & $6.43(p=0.011)$ & \\
\hline & HR(CR100) & $\mathrm{B}_{1}$ & 0.083 & 0.032 & $6.93(p=0.008)$ & 1.09 \\
\hline & & $\mathrm{B}_{0}$ & -11.2 & 4.25 & $6.95(p=0.004)$ & \\
\hline & CR100 & $\mathrm{B}_{1}$ & 0.104 & 0.037 & $7.90(p=0.005)$ & 1.11 \\
\hline & & $\mathrm{B}_{0}$ & -4.33 & 1.57 & $7.58(p=0.006)$ & \\
\hline St III:1, & HR & $\mathrm{B}_{1}$ & 0.179 & 0.059 & $9.24(p=0.002)$ & 1.20 \\
\hline \multirow[t]{5}{*}{ Max $120 \mathrm{~W}$} & & $\mathrm{~B}_{0}$ & -22.5 & 7.25 & $9.78(\mathrm{p}=0.002)$ & \\
\hline & RPE & $\mathrm{B}_{1}$ & 1.28 & 0.451 & $8.08(\mathrm{p}=0.004)$ & 3.60 \\
\hline & & $\mathrm{B}_{0}$ & -18.4 & 6.38 & $8.30(\mathrm{p}=0.004)$ & \\
\hline & CR10 & $\mathrm{B}_{1}$ & 1.045 & 0.361 & $8.36(p=0.004)$ & 2.84 \\
\hline & & $\mathrm{B}_{0}$ & -4.60 & 1.47 & $9.82(\mathrm{p}=0.002)$ & \\
\hline St III:1, & HR & $\mathrm{B}_{1}$ & 0.173 & 0.063 & $7.60(p=0.006)$ & 1.19 \\
\hline \multirow[t]{3}{*}{ Sub-max $120 \mathrm{~W}$} & & $\mathrm{~B}_{0}$ & -24.6 & 8.68 & $8.06(\mathrm{p}=0.005)$ & \\
\hline & CR10 & $\mathrm{B}_{1}$ & 1.323 & 0.505 & $8.86(\mathrm{p}=0.009)$ & 3.75 \\
\hline & & $\mathrm{B}_{0}$ & -5.31 & 1.84 & $8.34(p=0.004)$ & \\
\hline St III:2, & HR(RPE) & $\mathrm{B}_{1}$ & 0.075 & 0.032 & $5.63(\mathrm{p}=0.018)$ & 1.08 \\
\hline \multirow[t]{9}{*}{$125 \mathrm{~W}$} & & $\mathrm{~B}_{0}$ & -10.9 & 4.65 & $5.50(\mathrm{p}=0.019)$ & \\
\hline & RPE & $\mathrm{B}_{1}$ & 1.34 & 0.595 & $5.09(\mathrm{p}=0.024)$ & 3.83 \\
\hline & & $\mathrm{B}_{0}$ & -20.8 & 9.22 & $5.08(\mathrm{p}=0.024)$ & \\
\hline & CR100 & $\mathrm{B}_{1}$ & 0.098 & 0.046 & $4.43(\mathrm{p}=0.035)$ & 1.10 \\
\hline & & $\mathrm{B}_{0}$ & -3.90 & 1.85 & $4.46(p=0.035)$ & \\
\hline & HR(CR10) & $\mathrm{B}_{1}$ & 0.103 & 0.045 & $5.19(\mathrm{p}=0.023)$ & 1.11 \\
\hline & & $\mathrm{B}_{0}$ & -15.1 & 6.72 & $5.08(\mathrm{p}=0.024)$ & \\
\hline & CR10 & $\mathrm{B}_{1}$ & 1.033 & 0.438 & $5.55(\mathrm{p}=0.018)$ & 2.81 \\
\hline & & $\mathrm{B}_{0}$ & -5.30 & 2.30 & $5.32(\mathrm{p}=0.021)$ & \\
\hline
\end{tabular}

